\title{
A Combined Low-pressure Hydrogen Peroxide Evaporation plus Hydrogen Plasma Treatment Method for Sterilization - Part 1: Characterization of the Condensation Process and Proof-of-Concept
}

\begin{tabular}{|c|c|}
\hline Journal: & Plasma Processes and Polymers \\
\hline Manuscript ID & ppap.201600198.R1 \\
\hline Wiley - Manuscript type: & Full Paper \\
\hline Date Submitted by the Author: & 22-Dec-2016 \\
\hline Complete List of Authors: & $\begin{array}{l}\text { Stapelmann, Katharina; Ruhr-Universitat Bochum, Biomedical Applications } \\
\text { of Plasma Technology } \\
\text { Fiebrandt, Marcel; Ruhr-Universitat Bochum, Electrical Engineering and } \\
\text { Plasma Technology } \\
\text { Lackmann, Jan-Wilm; Ruhr-Universitat Bochum, Biomedical Applications of } \\
\text { Plasma Technology; Ruhr-Universitat Bochum, Electrical Engineering and } \\
\text { Plasma Technology } \\
\text { Raguse, Marina; Deutsches Zentrum fur Luft und Raumfahrt, Institute of } \\
\text { Aerospace Medicine, Radiation Biology Department, Space Microbiology } \\
\text { Research Group } \\
\text { Postema, Michiel; Polska Akademia Nauk, Institute of Fundamental } \\
\text { Technological Research; University of the Witwatersrand, School of } \\
\text { Electrical and Information Engineering, Chamber of Mines Building } \\
\text { Moeller, Ralf; Deutsches Zentrum fur Luft und Raumfahrt, Institute of } \\
\text { Aerospace Medicine, Radiation Biology Department, Space Microbiology } \\
\text { Research Group } \\
\text { Awakowicz, Peter; Ruhr Universitaet Bochum, Electrical Engineering and } \\
\text { Plasma technology }\end{array}$ \\
\hline Keywords: & \\
\hline
\end{tabular}

\section{SCHOLARONE ${ }^{m}$ \\ Manuscripts}




\title{
A Combined Low-pressure Hydrogen Peroxide Evaporation plus Hydrogen Plasma Treatment Method for Sterilization - Part 1: Characterization of the Condensation Process and Proof-of-Concept
}

\author{
Katharina Stapelmann ${ }^{1,2}$, Marcel Fiebrandt ${ }^{2}$, Marina Raguse ${ }^{3}$, \\ Jan-Wilm Lackmann ${ }^{1,2}$, Michiel Postema ${ }^{4,5}$, Ralf Moeller ${ }^{3}$, \\ Peter Awakowicz ${ }^{2}$ \\ ${ }^{1}$ Biomedical Applications of Plasma Technology, Ruhr University Bochum, Germany \\ ${ }^{2}$ Institute for Electrical Engineering and Plasma Technology, Ruhr University \\ Bochum, Germany \\ ${ }^{3}$ German Aerospace Center (DLR e.V.), Institute of Aerospace Medicine, Radiation \\ Biology Department, Space Microbiology Research Group, Cologne (Köln), Germany \\ ${ }^{4}$ Institute of Fundamental Technological Research, Polish Academy of Sciences, \\ Warszawa, Poland \\ ${ }^{5}$ School of Electrical and Information Engineering, University of the Witwatersrand, \\ Johannesburg, South Africa \\ E-mail: katharina.stapelmann@rub.de
}

\begin{abstract}
A combined hydrogen peroxide evaporation and hydrogen low-pressure plasma treatment process for sterilization is introduced and investigated. The combination of hydrogen peroxide evaporation followed by hydrogen plasma treatment offers an advantage regarding sterilization in complex metal geometries or in sealed sterile bags, where plasma treatment alone faces challenges. Within this contribution, the droplet size and film homogeneity after condensation is investigated by optical diagnostics. Sterilization tests with common challenge organisms show the sterilization capabilities of the combined process in a process challenge device, mimicking the worstcase-scenario for plasma treatment in a small metal box. Furthermore, sterilization in sealed sterile bags clearly demonstrates the advantage of the combined process, showing full spore inactivation solely for the combined process.
\end{abstract}




\section{Introduction}

Cleaning, sterilization and decontamination of surfaces of various medical instruments and hospital equipment are key processes in the medical field and in pharmacological industry. The main objective of these processes is to remove, inactivate or destroy all pathogens in order to prevent infections, inflammations, and transmission of diseases. The most common sterilization technique in medical practice and hospitals is sterilization with moist heat, e.g. autoclaving. ${ }^{[1]}$ The sterilization process requires a high temperature of $121^{\circ} \mathrm{C}$, or $134^{\circ} \mathrm{C}$ if infectious proteins (prions) need to be destroyed, making it unsuitable for the sterilization of thermolabile or biodegradable materials. ${ }^{[2]}$ A study performed by Baxter et al. indicates that after standard procedures up to 1173 micrograms of protein per instrument ${ }^{[3]}$ remain on the processed instruments. In another study performed by the same group, ${ }^{[4]}$ protein residuals of $5-10 \mu \mathrm{g} / \mathrm{cm}^{2}$ even after stringent protocols were reported. Tissue residues sticking to the instruments through washing and inactivation processes are of major concern as surviving bacteria or prions can be carried over from one patient to another. However, the traditionally employed techniques suffer from certain limitations and are in many cases insufficient to guarantee complete elimination of pathogens at all, or only after serious damage of the treated objects themselves. Therefore, new sterilization techniques are urgently required. One promising alternative that gained increased attention is plasma sterilization. The capabilities of plasma sterilization to remove and inactivate proteins, bacteria, bacterial spores, and prions could be shown in several laboratory setups, e.g. ${ }^{[5,6,7]}$ Plasma is an ionized gas, consisting of several microbicidal components such as reactive species and (V)UV radiation. Plasmas can be ignited at different temperatures and pressures, opening up various fields of application. For most sterilization purposes, cold low-pressure plasmas offer the best solution as they can be ignited in a large volume with low gas temperatures. These conditions enable for the parallel treatment of large quantities of equipment as well as allowing the treatment of heat sensitive materials such as plastics, as demonstrated by Denis et al. by presenting the first commercial lowpressure plasma sterilization device for integration in a pharmaceutical filling line. ${ }^{[8]}$ Other so-called plasma sterilization systems, i.e. Sterrad (Johnson \& Johnson), employ vaporized hydrogen peroxide as sterilizing agent. ${ }^{[9,10]}$ The condensation of hydrogen peroxide is avoided. The plasma is ignited in a ring-shape around the process chamber. Active plasma species reach the objects to be treated by diffusion through the perforated electrode. Because the objects are not in direct contact to the plasma and the main sterilizing agent is hydrogen peroxide vapor, Lerouge et al. ${ }^{11]}$ stated that Sterrad and comparable systems are not plasma sterilizers.

An advantage of 'true' plasma sterilizer is that plasmas are capable of removing biological residues by etching, sputtering, and chemical sputtering. ${ }^{[12,13]}$ Biological material is volatilized by breaking chemical bonds and saturating them with species from the plasma, such as hydroxyl radicals or hydrogen atoms. In order to achieve a high amount of $\mathrm{OH}$ radicals, $\mathrm{O}$, and $\mathrm{H}$ atoms, Fumagalli et al. ${ }^{[14]}$ and Hayashi et Wiley-VCH 
al. ${ }^{[15]}$ employed another technique by using water vapor as process gas for low-pressure plasma sterilization and decontamination. Although plasma sterilization offers several advantages compared to the traditionally employed techniques, it is a challenge to sterilize small, complex metal geometries, due to shielding characteristics. Additionally, the efficacy of plasma against biological substrates such as aggregated proteins or multi-layered biofilms is limited. ${ }^{[16]}$ To overcome this problem, a two-step process is approached. Here, we present a novel process, combining hydrogen peroxide evaporation and subsequent condensation in a low-pressure chamber with a plasma sterilization process, leading to faster microbial inactivation as well as improved protein removal. At first, the evaporation process was studied and optimized by means of optical diagnostics. To test the efficiency and validate the functionality of disinfection or sterilization procedures bacterial endospores are frequently used as a biological dosimeter as they are one of the most resilient forms of a biological system. Here, Bacillus subtilis spores as a standard model system were treated on different substrates with evaporated hydrogen peroxide. In the next step, the commonly used challenge organisms Bacillus atrophaeus, Geobacillus stearothermophilus, and Aspergillus niger were treated in a process challenge device or wrapped in sterile bags as a proof-of-concept to test the plasma sterilization process for its compatibility to todays standards. A more detailed analysis of spore inactivation for different treatment conditions and investigation of etching efficiency and enzyme inactivation was performed and is presented in part 2. ${ }^{[17]}$

\section{Experimental procedures}

\subsection{Experimental setup}

The plasma source is described in detail in previous publications. ${ }^{[6,18]}$ Briefly, a capacitively coupled plasma reactor with a rectangular discharge chamber is used. The chamber is composed of the high-performance polymer PEEK (polyether-ether-ketone) with the inner dimensions $320 \mathrm{~mm} \times 220 \mathrm{~mm} \times 65 \mathrm{~mm}$ and a wall thickness of $15 \mathrm{~mm}$ resulting in a volume of approximately 4.5 l. A notch is shaped on the top side securing a sealing ring made of Viton ${ }^{\circledR}$. For optical investigation of the evaporated liquid, an acrylic glass chamber is used. The chamber is evacuated by a rotary vane pump (Oerlikon Trivac D 65 B). Pressure is measured by two manometers $(0.01 \mathrm{~Pa}-100 \mathrm{~Pa}$ : MKS Baratron $627 \mathrm{~B}$; $100 \mathrm{~Pa}-10 \mathrm{kPa}$ : MKS Baratron $627 \mathrm{D}$ ) and controlled by a butterfly valve (VAT Series 612). As process gases, argon, hydrogen, nitrogen, and oxygen can be supplied by 4 mass flow controllers with a gas flow rate of $20 \mathrm{sccm}$ (MKS MFC Type 1179). In this study, only hydrogen was applied in order to combine the reactive species delivered from hydrogen peroxide with the sporicidal (V)UV radiation produced by the hydrogen discharge. Hydrogen was previously found to be very efficient in inactivat-

ing bacterial spores. ${ }^{[8,19]}$. The discharge is driven by a generator at a frequency from the VHF-band of $81.36 \mathrm{MHz}$ and a power of $400 \mathrm{~W}$. Additionally, liquids can be evaporated into the system by an evaporator made of a $150 \mathrm{~mm}$ x $110 \mathrm{~mm}$ x $30 \mathrm{~mm}$ aluminum 

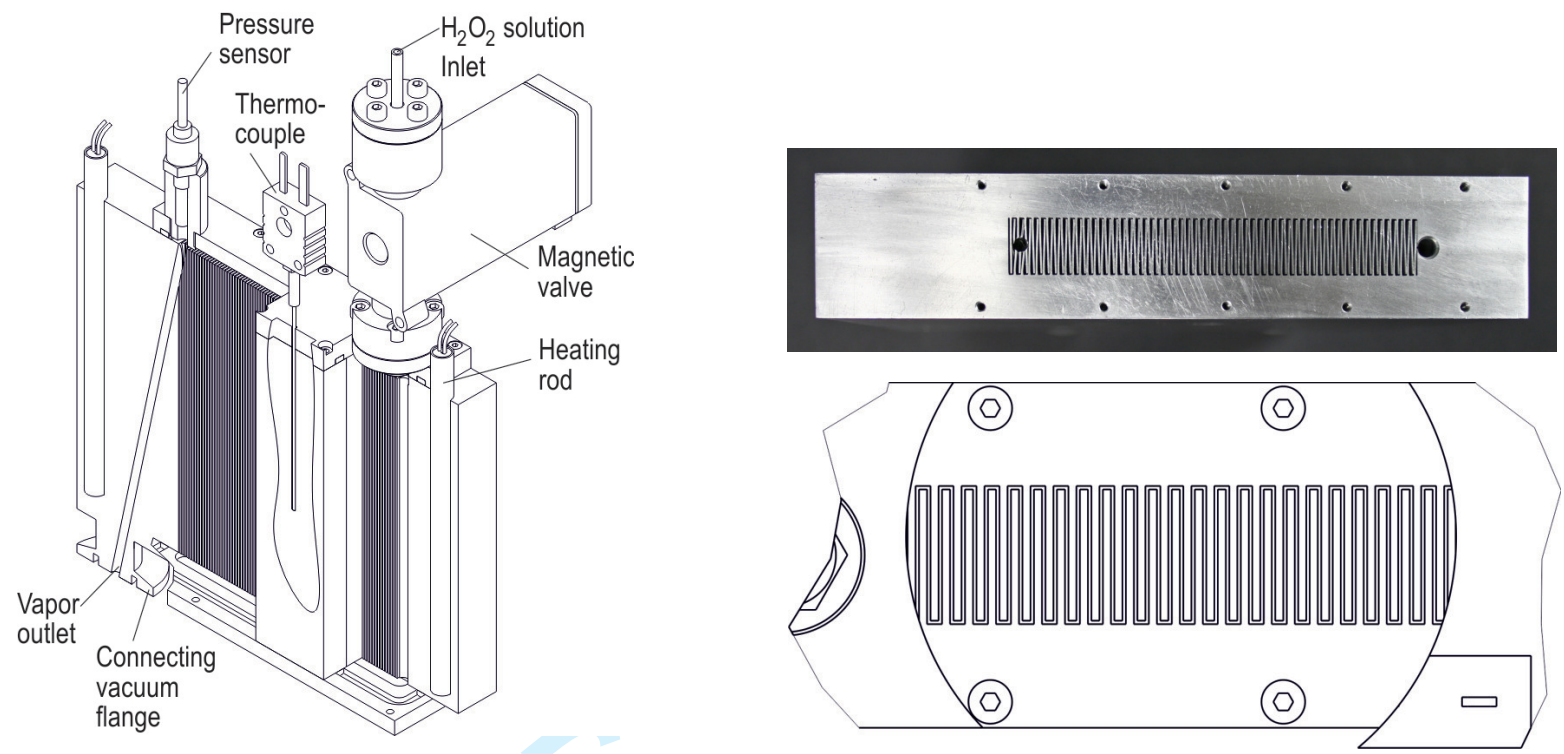

Figure 1. Sketch of the evaporator (left) and the meander-shaped rips of the evaporator (right).

block (see figure 1). Numerous meander-shaped ribs of $105 \mathrm{~mm}$ x $11.5 \mathrm{~mm}$ x $0.5 \mathrm{~mm}$ run through the material yielding a contact surface of $0.26 \mathrm{~m}^{2}$. Heat is induced by two heating rods inserted in two elongated bores on each verge of the evaporator. Three temperature sensors (Pt100) aligned on a horizontal line in the center, are connected to a PID controller, controlling the heating rods.

Defined amounts of liquids are provided by a syringe pump (Hamilton Precision Syringe Drive PSD/2) and injected through a magnetic valve into the evaporator. For evaporation, the system is evacuated below $10 \mathrm{~Pa}$. After closing the butterfly valve, the syringe pump injects the liquid through the evaporator into the chamber. The sequence of the combined process on the basis of a pressure curve is depicted in figure 2 . The maximum amount of vapor at saturation pressure in the chamber depends on the temperature and the volume. At $25^{\circ} \mathrm{C}(298.15 \mathrm{~K})$ and saturation pressure the chamber approximately contains $100 \mathrm{mg}$ of water vapor. By evaporating more than $100 \mu \mathrm{l}$ of water and assuming cooling of the gas near room temperature due to expansion into a larger volume, the chamber volume is oversaturated instantaneously and condensation occurs. Concerning $\mathrm{H}_{2} \mathrm{O}$, evaporating $1 \mathrm{ml}$ results in a film on the surfaces $\left(2 ' 110 \mathrm{~cm}^{2}\right.$ without any load) with about $1 \times 10^{19}$ molecules $/ \mathrm{cm}^{2}$. By using liquids like hydrogen peroxide, a large amount of radicals can be induced onto the surfaces and biological samples.

\subsection{Experimental conditions}

Experiments were performed vaporizing 1 to $4 \mathrm{ml}$ hydrogen peroxide with concentrations in the range of $7 \%(\mathrm{w} / \mathrm{w})$ up to $60 \%(\mathrm{w} / \mathrm{w})$. While the weight-per-weight percent Wiley-VCH 


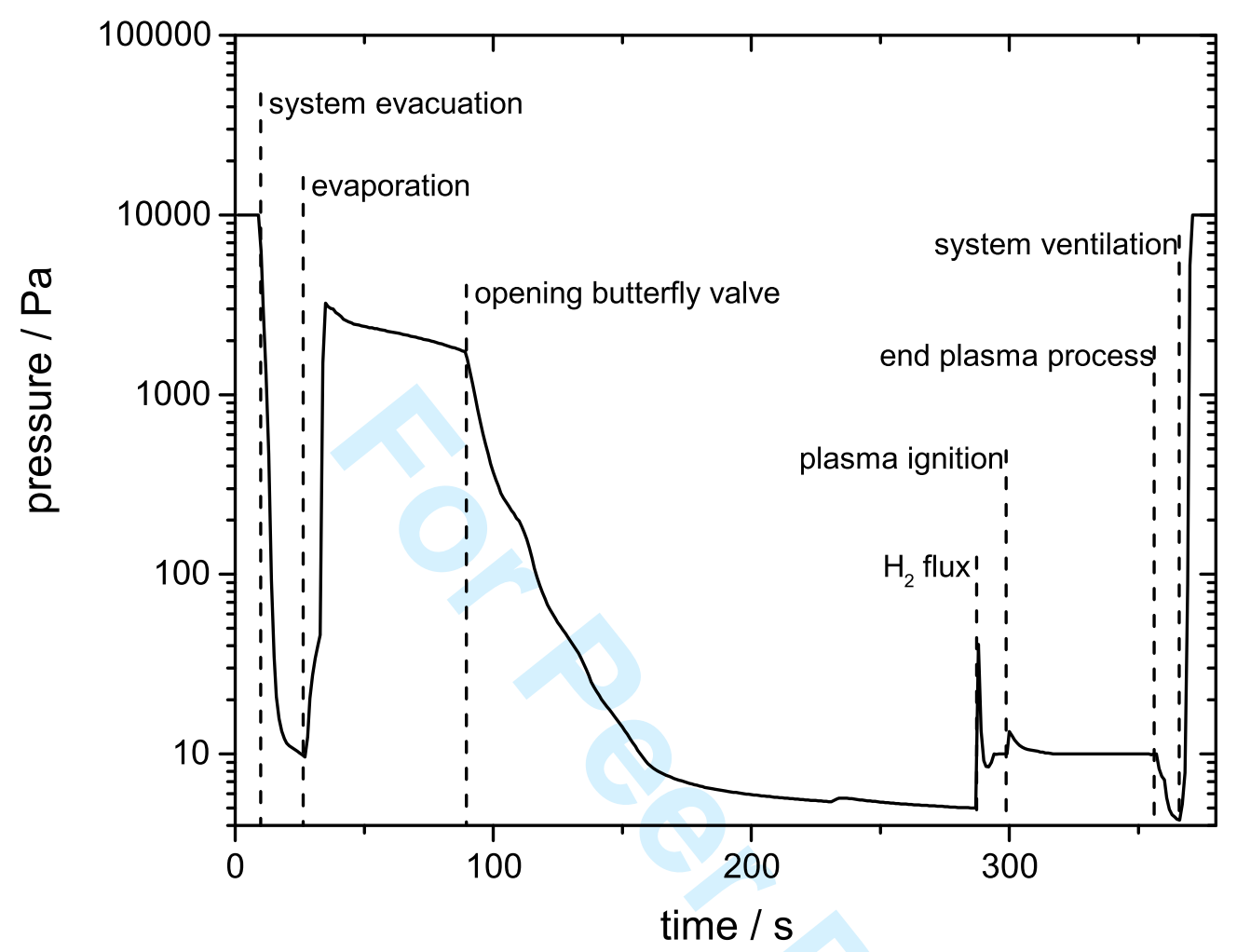

Figure 2. Sequence of the combined process: After system evacuation below $10 \mathrm{~Pa}, 4 \mathrm{ml}$ of $30 \% \mathrm{H}_{2} \mathrm{O}_{2}$ are evaporated at $120^{\circ} \mathrm{C}$. The butterfly valve is closed for $60 \mathrm{~s}$ and opened afterwards. After system evacuation below $5 \mathrm{~Pa}, 20 \mathrm{sccm} \mathrm{H}_{2}$ flux is applied at $10 \mathrm{~Pa}$. The plasma is ignited for $60 \mathrm{~s}$ at $400 \mathrm{~W}$. Afterwards, the system is vented again.

nomenclature is not the most intuitive, commercially available hydrogen peroxide is sold using this denotation. For references, a $30 \%(\mathrm{w} / \mathrm{w})$ hydrogen peroxide solution equals $9.79 \mathrm{M} \mathrm{H}_{2} \mathrm{O}_{2}$ at room temperature. Each milliliter used in an evaporation therefor equals $332.86 \mathrm{mg}$ vaporized hydrogen peroxide or $5.894 \times 10^{21}$ molecules in the chamber. Alternatively, samples were treated with a $\mathrm{H}_{2}$ plasma for $60 \mathrm{~s}$ or with a combination of both processes, combining the vaporization of hydrogen peroxide with a $\mathrm{H}_{2}$ plasma treatment. For plasma treatment, the power was kept constant at $P=400 \mathrm{~W}$ and the pressure at $p=10 \mathrm{~Pa}$. To characterize the film resulting from hydrogen peroxide evaporation and to optimize the evaporation process, two optical methods are applied as described in the following.

2.2.1. Investigation of the droplet size of the condensate The high-speed camera Photron Fastcam 2.1 in combination with the 12x zoom lens system and a 2.0x lense attachment (Navitar) was used to determine the droplet size of the condensate depending Wiley-VCH 


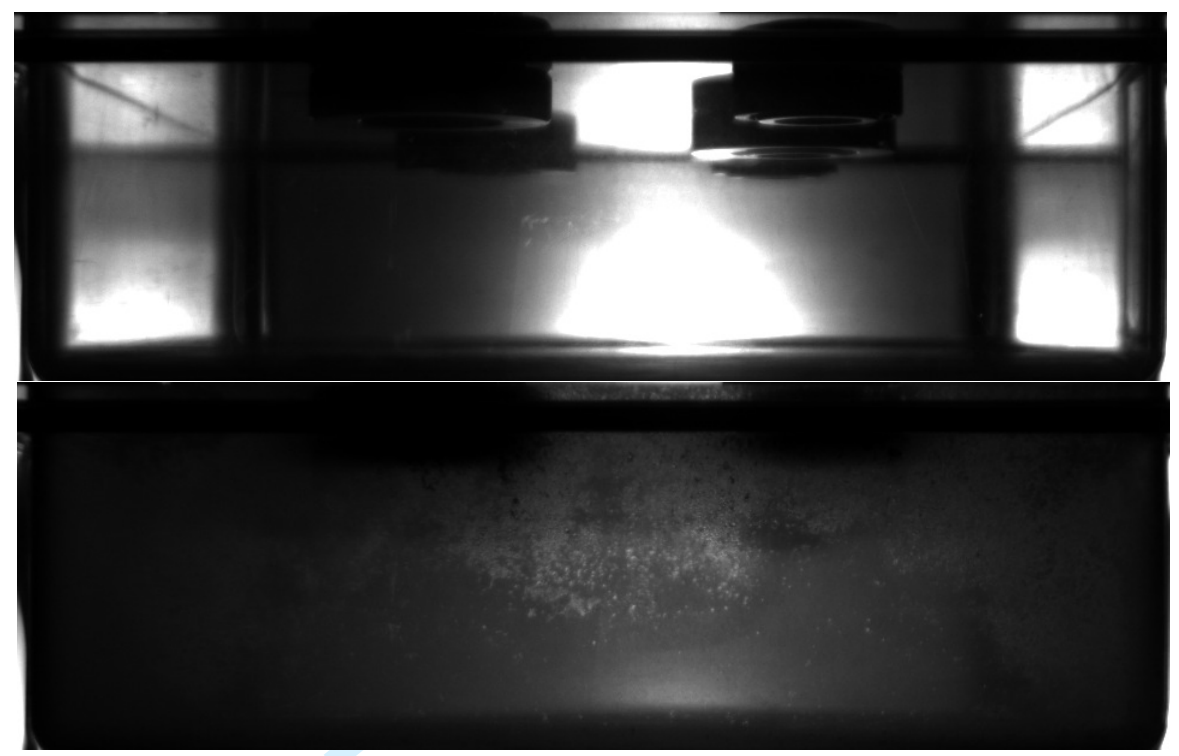

Figure 3. Camera view before (top) and after (bottom) evaporation of $3 \mathrm{ml} 30 \%$ (w/w) $\mathrm{H}_{2} \mathrm{O}_{2}$ at $120^{\circ} \mathrm{C}$. In the upper image the different ports to the chamber are visible.

on the evaporated amount of liquid, the velocity of the syringe drive, the starting pressure in the discharge chamber and the evaporation temperature. The settings of the camera were as follows: frame rate $500 \mathrm{fps}$, shutter $1 /$ frame sec, resolution $512 \times 512$. The working distance was kept constant at $27 \mathrm{~mm}$ to the chamber wall. As a light source, Storz technolight 270 in top view was applied.

The obtained pictures were evaluated by a custom-made LabView routine. The droplets were recognized automatically by the software and their size was determined. The parameters were varied as follows: (i) amount of hydrogen peroxide $(30 \%(\mathrm{w} / \mathrm{w})): 1 \mathrm{ml}$, $2 \mathrm{ml}, 3 \mathrm{ml}, 4 \mathrm{ml}$, (ii) temperature of the evaporator: $60^{\circ} \mathrm{C}, 90^{\circ} \mathrm{C}, 120^{\circ} \mathrm{C}$ (iii) velocity of the syringe drive: $4,6,8,10$ seconds per stroke, (iv) starting pressure in the discharge chamber: $10 \mathrm{~Pa}, 100 \mathrm{~Pa}, 500 \mathrm{~Pa}, 1000 \mathrm{~Pa}$. Only selected results are presented here due to the high amount of data acquired.

\subsubsection{Investigation of the condensate's homogeneity with different chamber load The} second method is used for characterization of film homogeneity depending on surface area, surface material, evaporated amount of liquid, and evaporation temperature. As evaporated liquids absorb and distract light, the intensity of a light source is observed with a CCD camera through an acrylic glass chamber during evaporation. Thus, thinner or inhomogeneous films result in lower absorption of the light as homogeneous or thicker films (see figure 3).

As light source, a current controlled tungsten ribbon lamp is used to ensure constant and stable light emission. The CCD camera (PCO Sensicam) is placed face to face with the light source. Images are taken with a constant exposure time of $1 \mathrm{~ms}$. To increase the surface area in the chamber thin slides $(152 \times 152 \times 2 \mathrm{~mm})$ of polystyrene 

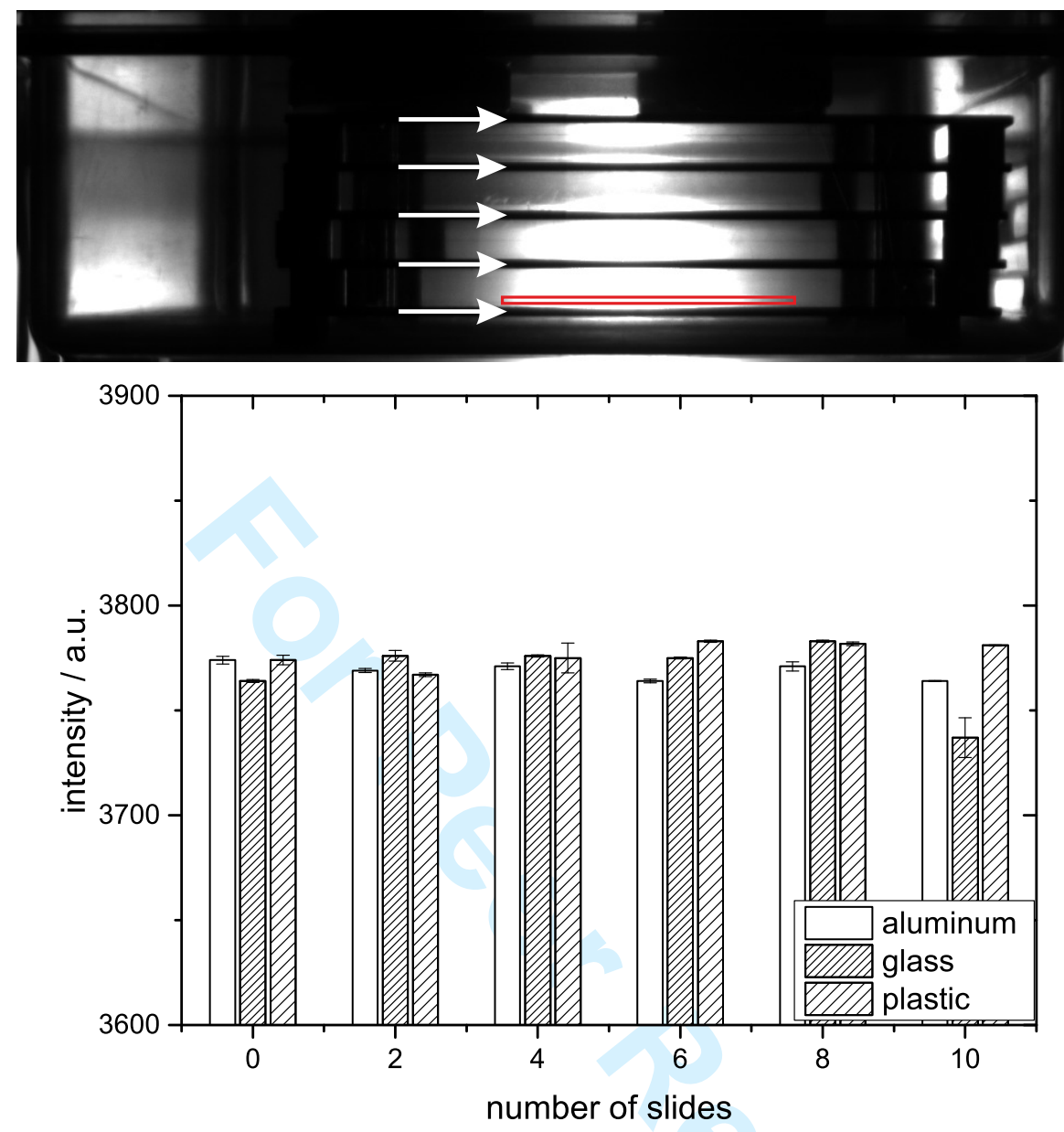

Figure 4. Top: Image of the chamber with 10 slides $(2$ stacks behind each other with 5 slides each). White arrows mark the position of the slides. The red line marks the averaged pixels for measuring the intensity; Bottom: Increasing number of slides does not influence the mean intensity value before evaporation of $\mathrm{H}_{2} \mathrm{O}_{2}$.

as plastic, aluminum or glass are placed inside. The materials have different thermal conductivity, influencing the condensation process. Thermal conductivity is given for the different materials at room temperature: polystyrene: $\lambda_{\mathrm{PS}}=0.1-0.13 \mathrm{~W} \cdot \mathrm{m}^{-1} \cdot \mathrm{K}^{-1},{ }^{[20]}$ aluminum: $\lambda_{\mathrm{Al}}=200 \mathrm{~W} \cdot \mathrm{m}^{-1} \cdot \mathrm{K}^{-1},{ }^{[21]}$ and glass: $\lambda_{\text {glass }}=0.84 \mathrm{~W} \cdot \mathrm{m}^{-1} \cdot \mathrm{K}^{-1}{ }^{[21]}$ Stacked slides are separated by distance spacers (diameter $12 \mathrm{~mm}$, height $7 \mathrm{~mm}$ ) made of the slides material. The surface area of the chamber is $2110 \mathrm{~cm}^{2}$. At maximum, 10 slides can be positioned ( 2 stacks behind each other with 5 slides each) resulting in an area increase inside the chamber of approximately $275 \%$ (see figure 4 ). The intensity can be influenced by reflection or distraction at the slides, scratches in the chamber material, etc. To minimize possible errors, the intensity is determined as mean value of 260 pixels where the slides do not influence the intensity signal (cf. figure 4). 


\subsection{Preparation of biological samples}

In order to obtain spores, vegetative cells of B. subtilis 168 (DSM 402) were grown in 2x Schaeffers sporulation medium at $37^{\circ} \mathrm{C}$ for 5 days. ${ }^{[22]}$ Spores were purified and stored as previously described. ${ }^{[23]}$ Isolation efficacy was checked by phase contrast microscopy. Spore samples were prepared on glass slides by covering the slides with $10^{6}$ spores. A detailed description of this method can be found in Raguse et al. ${ }^{[16]}$

Further sterilization tests were performed with the commonly used challenge organisms G. stearothermophilus (DSM 5934), B. atrophaeus (DSM 2277), and A. niger (DSM 1957). Spores of $G$. stearothermophilus are used as indicator organism for steam sterilization control. ${ }^{[26,27]}$ Spores of B. atrophaeus, until 2000 listed as B. subtilis, ${ }^{[28]}$ act as bio-indicator for gas sterilization, especially for ethylene oxide sterilization. ${ }^{[29]}$ Spores of the fungi $A$. niger show elevated resistance against radiation and UV radiation in particular. ${ }^{[30,31]}$ Samples of the aforementioned spores were prepared and evaluated at the Fraunhofer Institute for Process Engineering and Packaging (IVV), Freising. Details of the sample preparation can be found in. ${ }^{[5,24,32]}$ Each sample consists of a glass specimen holder with $10^{6}$ cell forming units in the mean. After treatment, the substrates are washed with a defined amount of Ringer/Tween's solution. A dilution series is made, pipetted onto agar medium, and after a few days of incubation the colony forming units (CFU) are counted. Each CFU represents one surviving cell. All experiments were performed in triplicates. Each data point shows the mean value and standard deviation of the triplicates.

\section{Results}

\subsection{Characterization of hydrogen peroxide evaporation and condensation}

While the combination of hydrogen peroxide evaporation and plasma treatment is promising, its combination adds an additional layer of complexity to the whole process. The hydrogen discharge of the VHF-CCP is well characterized, ${ }^{[25]}$ though the evaporation process has to be analyzed to evaluate optimal parameters.Figure 5 shows the relatively calibrated optical emission spectra of the hydrogen discharge and of the discharge when $4 \mathrm{ml}$ hydrogen peroxide were evaporated before. The difference of both spectra is depicted in the bottom of figure 5 and shows higher intensity of the $\mathrm{OH}(\mathrm{A}-\mathrm{X})$ transition and the Balmer emission after evaporating hydrogen peroxide.

Homogeneity, distribution, and droplet size of the condensate can be influenced by several parameters. The droplet size of the condensate depending on the evaporated amount of liquid, the velocity of the syringe drive (DSD = drive speed dispense), the starting pressure in the discharge chamber $\left(p_{\text {base }}\right)$, and the evaporation temperature $\left(T_{\mathrm{V}}\right)$ is studied with $30 \% \mathrm{H}_{2} \mathrm{O}_{2}$. The distribution and the homogeneity of the condensate while different surface materials are offered for condensation is further investigated dependent on evaporation temperature, liquid volume, surface area and different materials in the process chamber. 


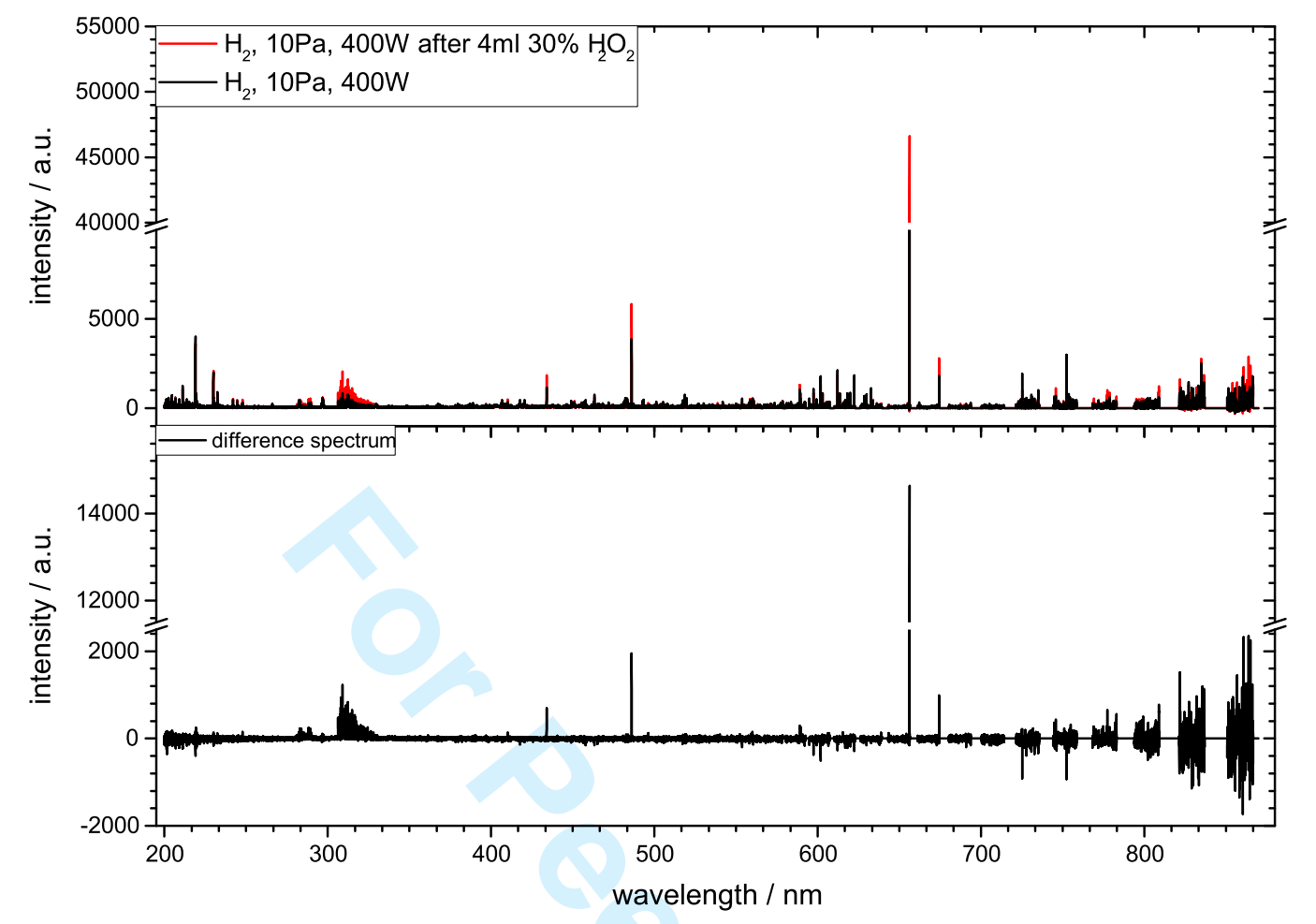

Figure 5. Relative calibrated spectra of the pure plasma process $\left(\mathrm{H}_{2}, 10 \mathrm{~Pa}, 400 \mathrm{~W}\right)$ and the combined process $\left(4 \mathrm{ml}, 120^{\circ} \mathrm{C}, 30 \% \mathrm{H}_{2} \mathrm{O}_{2}, \mathrm{H}_{2}, 10 \mathrm{~Pa}, 400 \mathrm{~W}\right.$ ) (top) and difference of both spectra (bottom). The difference spectrum shows stronger $\mathrm{OH}$ and Balmer emission after evaporation of $\mathrm{H}_{2} \mathrm{O}_{2}$.

3.1.1. Droplet size The evolution of droplet size of the condensate is investigated by a high-speed camera with a zoom lens. Obtained pictures (as an example, see figure 6) are evaluated automatically by a custom-made LabView routine. In figure 6 , the condensation process of $4 \mathrm{ml}$ hydrogen peroxide $30 \%$, evaporated at $90^{\circ} \mathrm{C}$, with DSD 4 and $p_{\text {base }}=10 \mathrm{~Pa}$ is shown as an example, corresponding to the black dots in figure 7 top left. It is clearly visible that the droplet size changes with time after condensation, at the beginning forming a quite homogeneous film with small droplet sizes, which run together to form bigger droplets.

Figure 7 depicts the temporal evolution of the mean droplet size of $\mathrm{H}_{2} \mathrm{O}_{2}$ after condensation. As a general trend, the droplet size rises with increasing time, the same accounts for the error bars. This is due to the fact that immediately after condensation, the smaller droplets run together, forming bigger droplets (see also figure 6). The variance in droplet sizes thus increases. For the different volumes of liquids, ranging from 1 to $4 \mathrm{ml}$, no significant difference can be observed. The mean droplet size varies between $0.1 \mathrm{~mm}^{2}$ and $0.3 \mathrm{~mm}^{2}$. In the next step, the base pressure was varied and no significant difference can be observed. Generally, the mean droplet size has a more homogeneous appearance. Although not significant, at least a trend is visible. With a base pressure of $p_{\text {base }}=1000 \mathrm{~Pa}$, the droplet size seems tolleye-verger than for the lower base pressures. 
A combined $\mathrm{H}_{2} \mathrm{O}_{2}$ evaporation and $\mathrm{H}_{2}$ plasma process for sterilization - Part 1
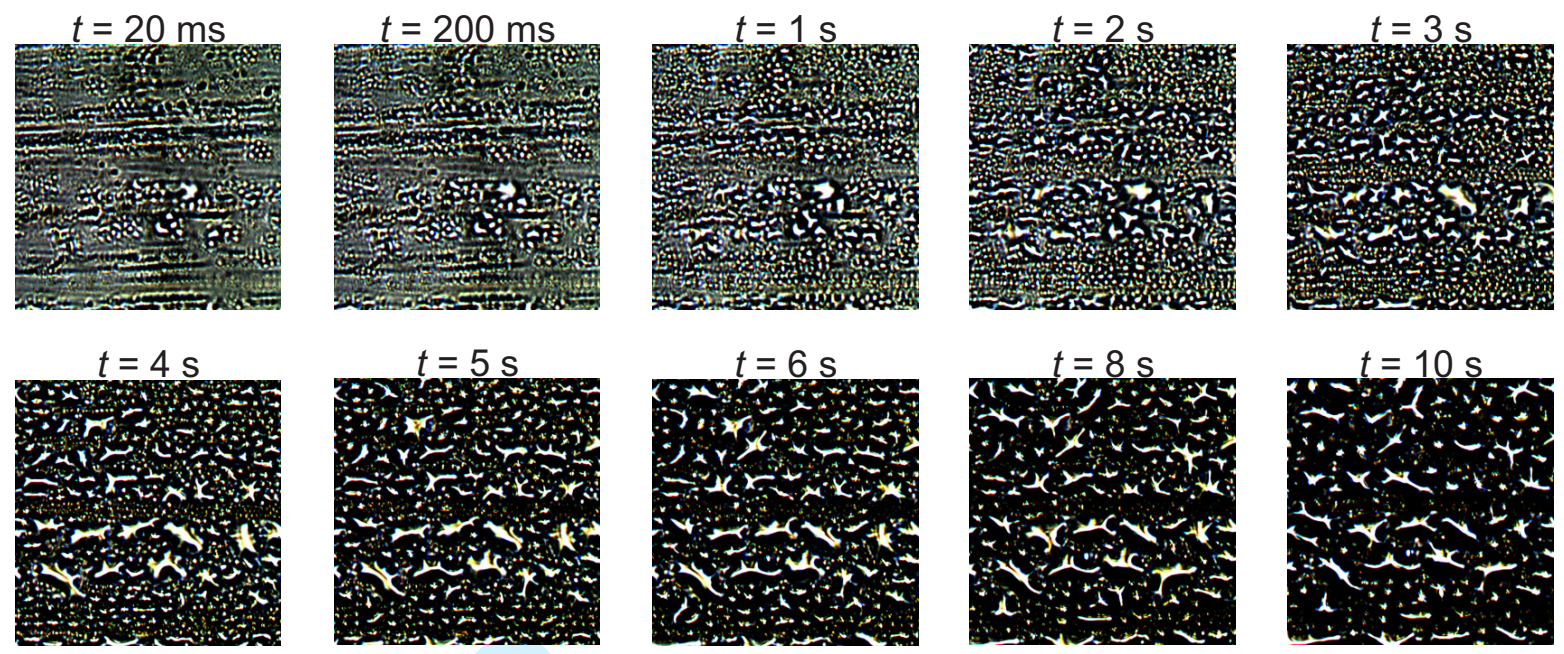

Figure 6. Temporal evolution of droplet size after condensation: Example images of the droplets at different time points after condensation of $4 \mathrm{ml}$ hydrogen peroxide $30 \%$, evaporated at $90^{\circ} \mathrm{C}$, with DSD 4 and $p_{\text {base }}=10 \mathrm{~Pa}$. These pictures were evaluated for different conditions, depicted in figure 7 .

Neither the injection velocity nor the temperature of the evaporator have an influence of the droplet size in the range we tested here. Generally, one can conclude that the parameters tested here do not have a significant influence on the mean droplet size, resulting in a stable process.

3.1.2. Influence of surface material in the process chamber Light intensity is measured after evaporation for three different materials inside the process chamber to evaluate if there is an influence of the evaporation temperature when further material is offered for condensation.

Figure 8 shows the resulting intensity after evaporating $1-3 \mathrm{ml}$ of $30 \% \mathrm{H}_{2} \mathrm{O}_{2}(30 \%$, evaporated at $120^{\circ} \mathrm{C}$ ) with different number of slides of aluminum, glass or polystyrene placed in the chamber. Comparable to the results depicted in figure 7 , no significant change was visible by varying the temperature of the evaporator for all three materials, hence only one temperature is depicted here.

By adding slides of different materials into the chamber, the overall surface area can be increased up to $275 \%$. In general, intensity is highest for the lowest amount of $\mathrm{H}_{2} \mathrm{O}_{2}$, i.e. $1 \mathrm{ml}$, and lowest for the amount of $3 \mathrm{ml} \mathrm{H}_{2} \mathrm{O}_{2}$, indicating that a better homogeneity or film thickness is achieved for higher amounts of the liquid. Whereas the intensity for $2 \mathrm{ml}$ and $3 \mathrm{ml}$ is at the beginning relatively close to each other, a bigger difference can be observed for $1 \mathrm{ml}$. Focusing on the $2 \mathrm{ml}$ and $3 \mathrm{ml}$ bars, there is no significant difference in intensity observable by increasing the number of slides for all materials up to 6 slides, meaning that the homogeneity or thickness of the condensate film is not affected significantly. This is not the case for $1 \mathrm{ml}$ hydrogen peroxide, where intensity is increasing directly after placing 2 slidesin the chamber. As a result, the homogeneity 

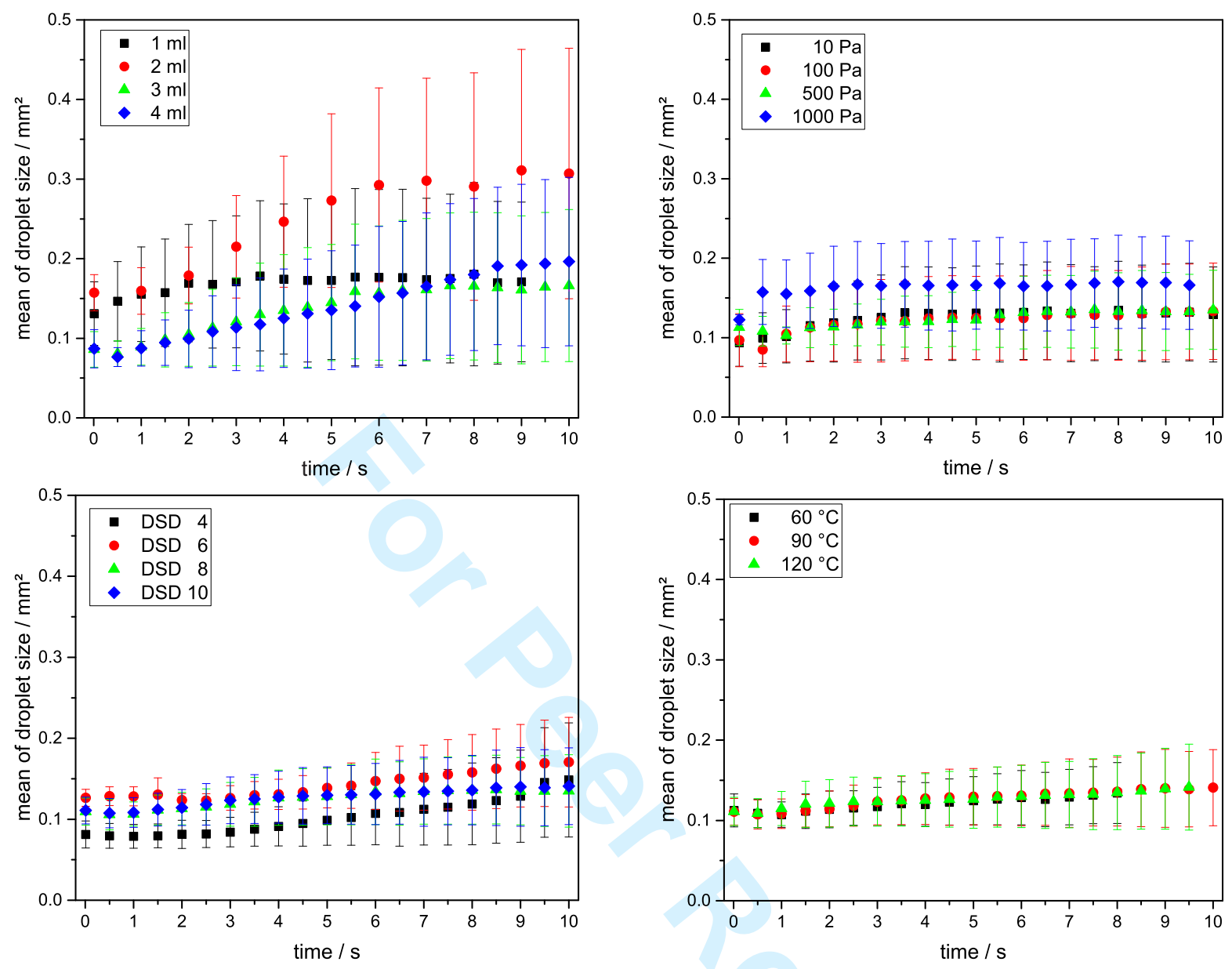

Figure 7. Temporal evolution of mean droplet size for different conditions: Top Left: depending on the amount of evaporated $\mathrm{H}_{2} \mathrm{O}_{2}, T_{\mathrm{V}}=90^{\circ} \mathrm{C}$, DSD $4, p_{\text {base }}$ $=10 \mathrm{~Pa}$. Top Right: for different starting pressures in the process chamber. $T_{\mathrm{V}}=$ $120^{\circ} \mathrm{C}$, DSD $4,2 \mathrm{ml} \mathrm{H}_{2} \mathrm{O}_{2}$. Bottom left: for different liquid injection velocities. $T_{\mathrm{V}}=$ $90^{\circ} \mathrm{C}, p_{\text {base }}=10 \mathrm{~Pa}, 4 \mathrm{ml} \mathrm{H} \mathrm{H}_{2}$. Bottom right: for different evaporator temperatures. $p_{\text {base }}=10 \mathrm{~Pa}$, DSD 4, $4 \mathrm{ml} \mathrm{H}_{2} \mathrm{O}_{2}$. For all experiments: $c\left(\mathrm{H}_{2} \mathrm{O}_{2}\right)=30 \%$

or film thickness is not sufficient when evaporating only $1 \mathrm{ml} \mathrm{H}_{2} \mathrm{O}_{2}$. Looking at the $2 \mathrm{ml}$ bars, the intensity doubles in case of 8 aluminum slides, meaning a strong decrease in the film thickness. Interestingly, neither glass nor plastic show the same effect at 8 slides. Adding 10 slides, the intensity with aluminum does not change compared to 8 slides. Similar to aluminum, the intensity with glass slides now strongly increases, and only the intensity with plastic slides remains unaffected. Reducing the amount of liquid to $1 \mathrm{ml}$ leads to a stronger dependence of the intensity on the surface area. On the other hand, evaporating $3 \mathrm{ml}$ reduces the intensity increase and thereby the dependence on the surface area which in turn means a more homogeneous and thicker condensate film. Overall, one might expect a linear increase of the intensity with increasing number of slides and not a strong increase followed by only minor changes, which is sometimes visible. This might be due to the fact, that the evaporation is also affected by position and shape of additional objects in the chamber. As the evaporation process is very 

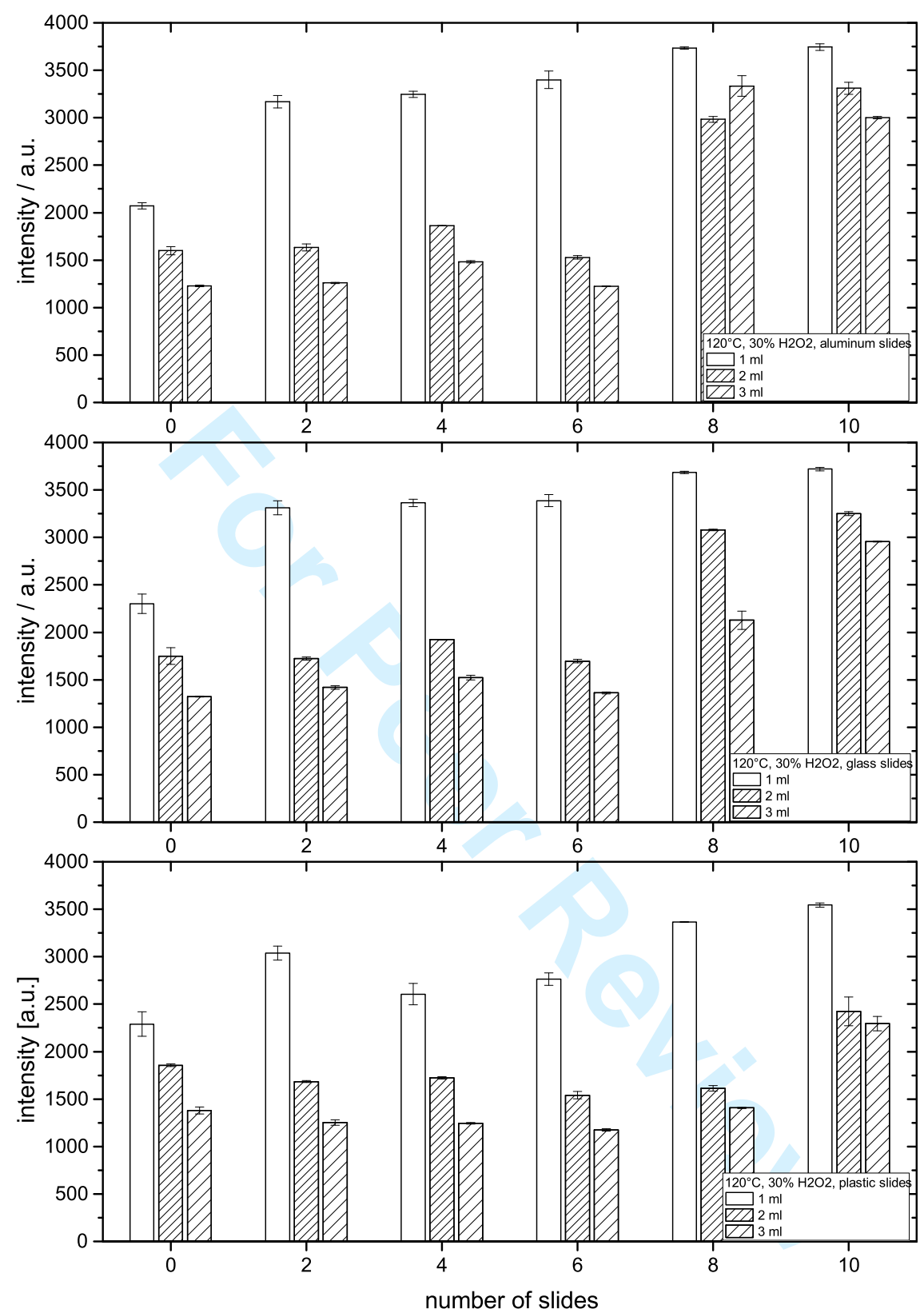

Figure 8. Influence of surface area, surface material and amount of evaporated liquid onto film homogeneity and/or thickness (the lower the intensity, the thicker the liquid film due to absorption and distraction of light): Intensity is depicted for number of slides from 0 to 10 slides of aluminum, glass, and polystyrene as plastic. The amount of hydrogen peroxide $\left(c=30 \%, T_{\mathrm{V}}=120^{\circ} \mathrm{C}\right)$ is varied from 1 to $3 \mathrm{ml}$.

complex (change of pressure, temperature, volume, concentration, surface area and material), the results can only indicate a general trend that homogeneous treatment of objects with large surfaces and different surface materials is possible. For this purpose, the amount of liquid has to be at least $3 \mathrm{ml}$ as long as the surface area of the treated objects is below $4500 \mathrm{~cm}^{2}$. 


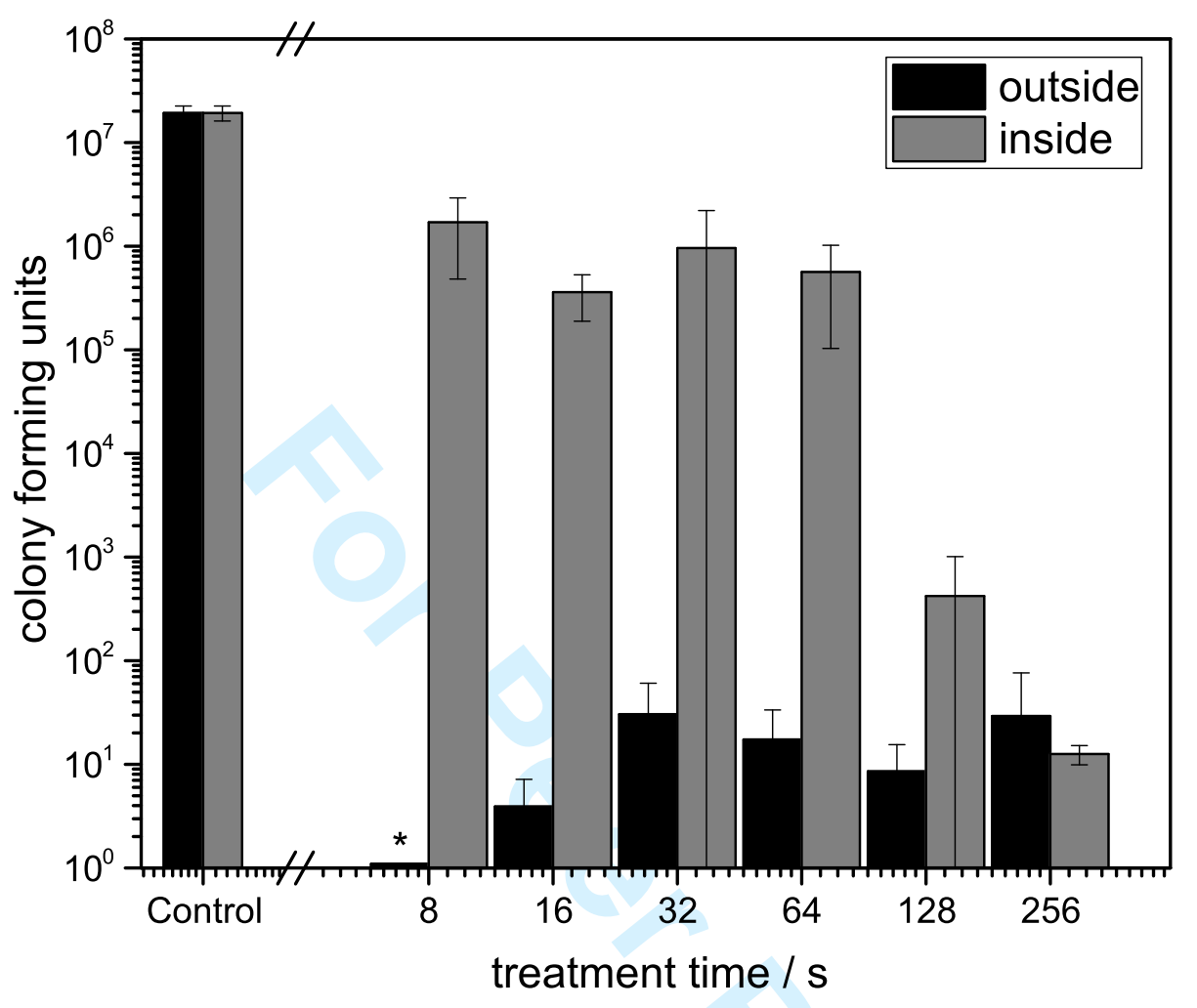

Figure 9. Spore inactivation in a PCD: Colony forming units of Bacillus atrophaeus inside and outside a process challenge device (PCD). Experimental conditions were: $4 \mathrm{ml} \mathrm{H}_{2} \mathrm{O}_{2} 30 \%$, DSD $4, p_{\text {base }}=10 \mathrm{~Pa}, T_{\mathrm{V}}=90^{\circ} \mathrm{C} ; 20 \mathrm{sccm} \mathrm{H}$, $P=400 \mathrm{~W}, p=10 \mathrm{~Pa}$. The asterisks indicate CFU below detection limit (full spore inactivation).

\subsection{Inactivation of bacterial spores}

3.2.1. Proof-of-concept: Inactivation of spores in a process challenge device A process challenge device (PCD) is designed in order to mimic worst case situations for plasma sterilization. Due to the shielding characteristics of plasma, small, complex metal geometries pose a challenge for plasma sterilization. Hence, the PCD is a cylindrical metal container with three small slits with a width of $0.3 \mathrm{~mm}$ in the lid. For sterilization tests, spores of Bacillus atrophaeus were used. Spores deposited on glass slides were placed inside and outside the PCD and treated with the combined $\mathrm{H}_{2} \mathrm{O}_{2}$ and $\mathrm{H}_{2}$-plasma process. Time-dependent spore inactivation is depicted in figure 9.

Samples placed outside the PCD, thus treated directly by $\mathrm{H}_{2} \mathrm{O}_{2}$ and plasma, show a faster spore inactivation than samples placed inside the PCD. A reduction of 6 orders of magnitude, i.e. corresponding to the definition of sterile, is achieved in the first $8 \mathrm{~s}$ of treatment outside the PCD, whereas sterilizpetjoncof samples placed inside the PCD took 
about $256 \mathrm{~s}$. It is evident that CFU assays have an inherently high internal variance especially for very small CFU numbers. Here, about 10 surviving spores were counted regardless of treatment times, which is well within the internal variance of the test and about the bottommost detection limit. Therefore, differences between the various treatment time points can be deemed not significantly but rather due to a few spores capable of surviving the sterilization process due to stacked spore layers and shadowing. In comparison, significant decrease in CFUs of samples treated inside the PCD was only observed after $128 \mathrm{~s}$.

3.2.2. Proof-of-concept: Inactivation of spores in sealed sterile bags State-of-the-art for sterilization of medical instruments, implants, and utensils, is the sterilization in sealed sterile bags. After the process the sterilized object remains sterile inside the sealed bag. The sterile bag consists of two materials, one side plastic film, the other side a gas-permeable Tyvek ${ }^{\circledR}$ sheet. In order to test the plasma sterilization process for its compatibility to todays standard, glass slides are contaminated and sealed in sterile bags before plasma treatment. Spores of Geobacillus stearothermophilus serve as a biological indicator for directly monitoring the lethality of sterilization processes including steam sterilization $^{[27]}$ and hydrogen peroxide gas plasmas ${ }^{[33]}$ and therefore it was used for this study.

Figure 10 shows the inactivation results inside and outside sealed sterile bags. Inactivation efficiency of $G$. stearothermophilus spores inside the bags was nearly as efficient as outside the bags when using hydrogen plasma. With evaporated hydrogen peroxide, inactivation outside the sterile bags was efficient, whereas inside the sterile bags no inactivation was observed. The combination of hydrogen peroxide and hydrogen plasma resulted in total inactivation both inside and outside the sterile bags after $60 \mathrm{~s}$ treatment time, clearly highlighting the advantage of the combined process.

To this end, bacterial spores of different strains (B. subtilis, B. atrophaeus, $G$. stearothermophilus) were tested. With the next experiments, also fungal spores of Aspergillus niger were included. As shown in figure 11, full spore inactivation can be achieved independent of the tested strain. 


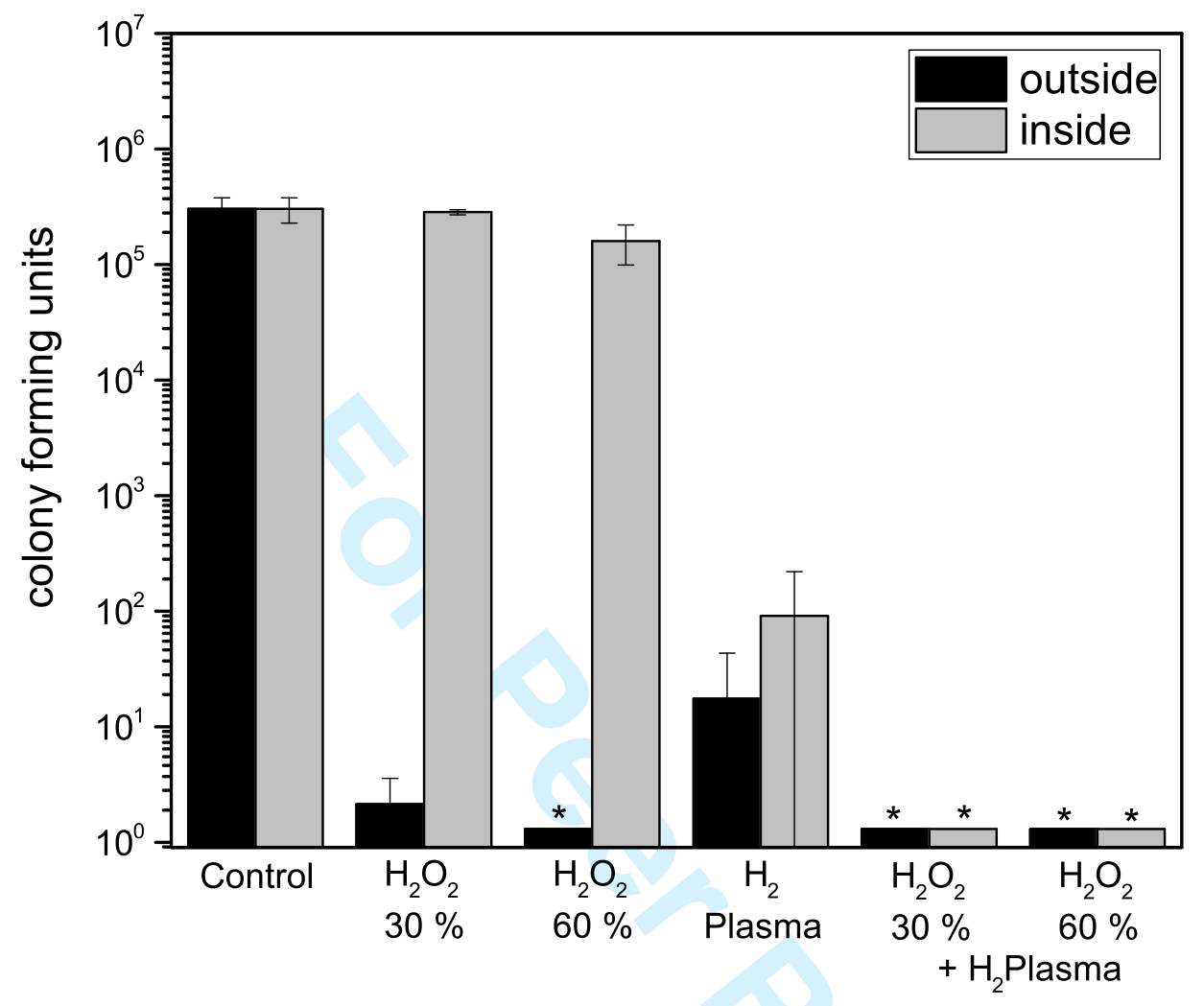

Figure 10. Spore inactivation in sterile bags: Colony forming units of Geobacillus stearothermophilus inside and outside sterile bags after $60 \mathrm{~s}$ treatment time. Experimental conditions were: $4 \mathrm{ml} \mathrm{H}_{2} \mathrm{O}_{2}$, DSD $4, p_{\text {base }}=10 \mathrm{~Pa}, T_{\mathrm{V}}=120^{\circ} \mathrm{C} ; 20 \mathrm{sccm}$ $\mathrm{H}_{2}, P=400 \mathrm{~W}, p=5 \mathrm{~Pa}$. The asterisks indicate CFU below detection limit (full spore inactivation). 


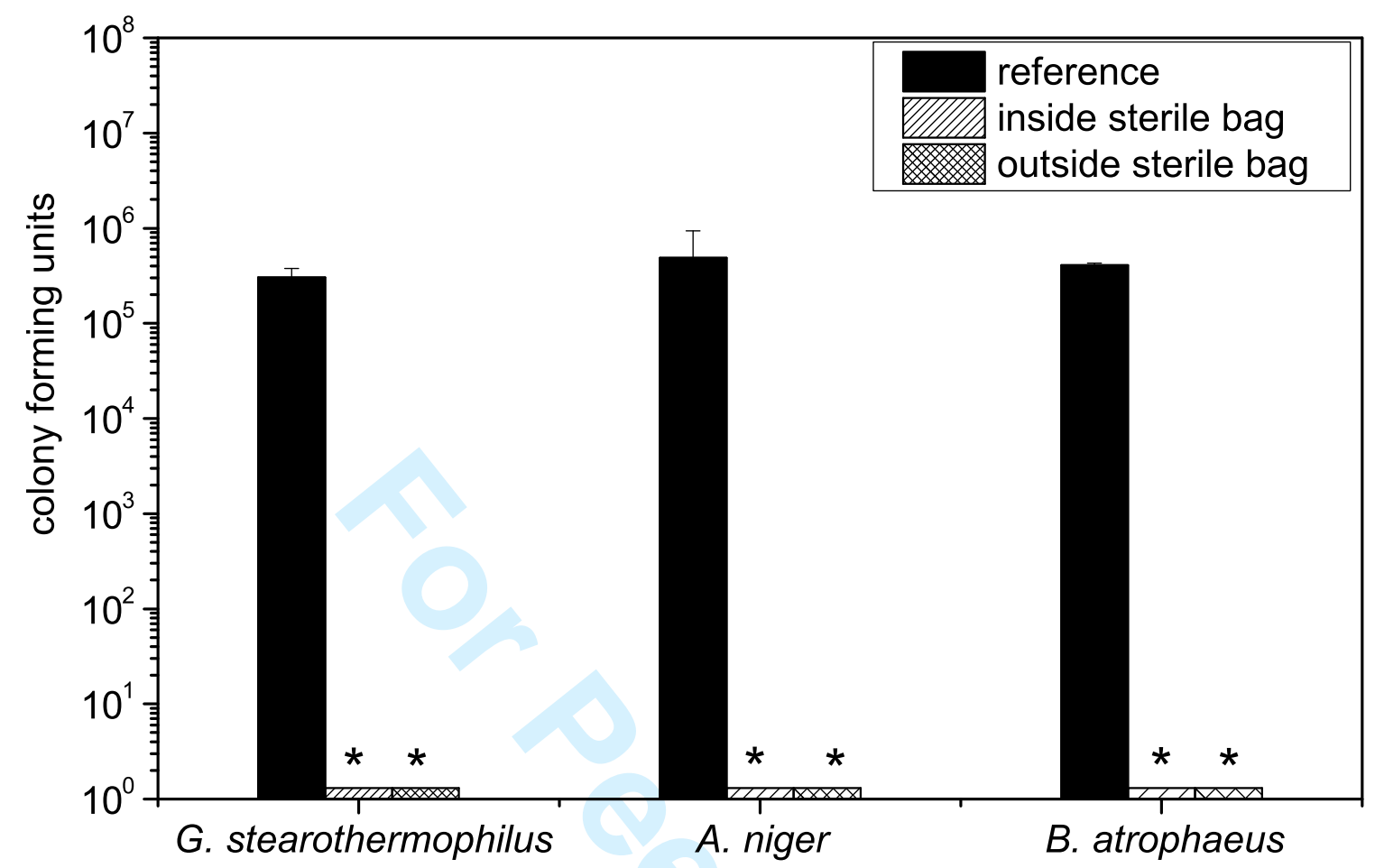

Figure 11. Bacterial and fungal spore inactivation in sterile bags: Colony forming units of Geobacillus stearothermophilus, Aspergillus niger and Bacillus atrophaeus inside and outside sterile bags after $60 \mathrm{~s}$ treatment time. Experimental conditions were: $4 \mathrm{ml} \mathrm{H}_{2} \mathrm{O}_{2} 30 \%$, DSD $4, p_{\text {base }}=10 \mathrm{~Pa}, T_{\mathrm{V}}=120^{\circ} \mathrm{C} ; 20 \mathrm{sccm} \mathrm{H}$, $P=400 \mathrm{~W}, p=5 \mathrm{~Pa}$. The asterisks indicate $\mathrm{CFU}$ below detection limit (full spore inactivation). 


\section{Discussion}

\subsection{Influence of evaporation parameters on the condensation}

The condensation of the evaporated liquid is investigated by two optical methods in order to gain insight to droplet size and film homogeneity. Within the parameter range tested here, no significant differences could be observed for the droplet size depending on evaporated volume, evaporation temperature, base pressure, and injection velocity. The evaporation with subsequent condensation process appears insensitive on the tested parameter range, thus it can be seen as a stable process. Nevertheless, there is a trend that with higher evaporation temperatures the droplet size distribution appears more homogeneous. Furthermore, the combination of selected volume and evaporation temperature plays a role. Similar accounts for the investigation of film homogeneity. However, the characterization of the condensate film shows a strong influence of the film homogeneity as result of the surface area and the surface material. With increasing surface area, the condensation film per area shrinks as the same amount of liquid has to distribute onto a larger surface. Additionally, this effect is enhanced for aluminum surfaces, compared to glass or plastic. A possible explanation is the condensation on cold spots. Materials with high thermal conductivity like aluminum can distribute induced heat very fast over the whole object. Thus, energy released by condensation on aluminum will not only heat the condensation spot, but the whole object. Thereby, the aluminum objects have only a minor increase in temperature and condensate on the condensation spot will have a reduced evaporation rate back into the volume. On the other hand, materials with low thermal conductivity like glass or plastic cannot transfer the induced condensation energy over the whole object effectively. This results in a temperature increase at the condensation spot leading to a higher evaporation rate and thereby to a thinner condensation film. Considering this, it is reasonable that the condensate film on the chamber wall observed by the CCD is reduced with increasing aluminum surface area, as more vapor condensates on aluminum than on the plastic chamber walls. On the other hand, this effect is reduced with glass or plastic, as less condensation takes place on both materials leading to a higher film thickness at the walls.

The evaporation and condensation is very complex as the pressure, volume, particle density, and temperature of the liquid in the volume is constantly changing during the whole process. Hence, a simplification of the system due to constant state variables is not possible (i.e. isothermal or isobaric processes). Furthermore, the mixture of $\mathrm{H}_{2} \mathrm{O}$ and $\mathrm{H}_{2} \mathrm{O}_{2}$ is seen as a binary system from a thermodynamic point of view, having different vapor pressures and boiling temperatures. Thereby, the composition of the condensate changes during the condensation process, yielding an increased $\mathrm{H}_{2} \mathrm{O}_{2}$ concentration in the condensate layer. Inactivation tests of bacterial spores reveal the advantage of the combined process. Whereas inactivation of spores sealed in sterile bags was not achieved with $\mathrm{H}_{2} \mathrm{O}_{2}$ or plasma alone, the combination of both led to full spore inactivation. 
During condensation, following surface reaction can occur: ${ }^{[34]}$

$$
2 \mathrm{H}_{2} \mathrm{O}_{2} \rightarrow 2 \mathrm{H}_{2} \mathrm{O}+\mathrm{O}_{2}
$$

Combined with plasma, which acts in addition as sterilizing agent itself, further chemical reactions may occur, leading to the formation of atomic oxygen and the hydroxyl radical directly on the sample surface. Condensing hydrogen peroxide on surfaces has already been demonstrated to enhance spore inactivation compared to using gaseous hydrogen peroxide. Exact inactivation efficacy depends on the hydrophobicity of the spores in question with more hydrophilic spores being easier wetted and thereby inactivated with condensing hydrogen peroxide [35]. Furthermore, Pruss et al. discuss potential application of gaseous compared to condensing hydrogen peroxide and while the latter might enhance inactivation efficacy against a mixed microfauna, removal of condensed hydrogen peroxide is discussed as problematic. Here, the two-step process where condensation of hydrogen peroxide is followed by a hydrogen plasma process, is clearly advantageous regarding the removal of hydrogen peroxide residuals. Another advantage of the $\mathrm{H}_{2} \mathrm{O}_{2}$ condensation process is shown for the removal of proteinaceous material from the surface, leading to a removal offset of $2 \mu \mathrm{m}$ due to the strong oxidizing capabilities of $\mathrm{H}_{2} \mathrm{O}_{2}$, as presented in part 2 of the manuscript sequence. ${ }^{[17]}$ In the same study, further biological investigations of the combined process are presented and discussed. Taking into account the typical spore size of $1 \mu \mathrm{m}, \mathrm{H}_{2} \mathrm{O}_{2}$ pre-treatment can help to achieve inactivation even for several layers of bacteria. We could show in previous studies, that for screws contaminated dropwise with approximately $10^{8}$ spores of Bacillus subtilis, resulting in approximately 25 layers of spores, the $\mathrm{LD}_{90}$ value decreases from $19.7 \mathrm{~s}$ for $\mathrm{H}_{2}$ plasma treatment to $9.2 \mathrm{~s}$ if the combined process with hydrogen peroxide $(30 \%)$ is applied. ${ }^{[6]}$

\section{Conclusions}

In summary, the combined process of evaporated and condensated hydrogen peroxide followed by a low-pressure hydrogen plasma treatment is an effective and fast way to inactivate spores on various surfaces as well as in sealed sterile bags. Based on the combination of both effects, this process is a promising technique for future plasma sterilization applications.

\section{Acknowledgements}

The authors like to thank Andrea Schröder (DLR), Maren Melzer (RUB) and Sabrina Baldus (RUB) for technical assistance and Charles Rizk (RUB) for providing the evaporator. Funding of the DFG within the frame of the package project PlasmaDecon PAK 728 to P.A., M.F., and K.S. (AW 7/3-1), M.R. and R.M. (MO 2023/2-1) is gratefully acknowledged. This work was supported in part by grants from the German Aerospace Center (DLR-FuE-Projekt ISS LIFE, Programm RF-FuW, Teilprogramm 475) to M.R. and R.M. 


\section{References}

[1] van Doornmalen, J. and Kopinga, K., 2008, Review of surface steam sterilization for validation purposes, American Journal of Infection Control, 36(2), 86-92

[2] Lewis, S. and McIndoe A. K., 2004, Cleaning, disinfection and sterilization of equipment, Anaesthesia \& Intensive Care Medicine, 5(11), 360-363

[3] Baxter, RL and Baxter, HC and Campbell, GA and Grant, K and Jones, A and Richardson, P and Whittaker, G, 2006, Quantitative analysis of residual protein contamination on reprocessed surgical instruments, Journal of Hospital Infection 63(4), 439-444

[4] Baxter, H. C., Campbell, G. A., Richardson, P. R., Jones, A. C., Whittle, I. R., Casey, M., Whittaker, A. G., Baxter, R. L., 2006, Surgical instrument decontamination: Efficacy of introducing an argon:oxygen RF gas-plasma cleaning step as part of the cleaning cycle for stainless steel instruments, IEEE Transactions on Plasma Science 34, 1337-1344

[5] von Keudell, A. and Awakowicz, P. and Benedikt, J. and Raballand, V. and Yanguas-Gil, A. and Opretzka, J. and Fltgen, C. and Reuter, R. and Byelykh, L. and Halfmann, H. and Stapelmann, K. and Denis, B. and Wunderlich, J. and Muranyi, P. and Rossi, F. and Kylián, O. and Hasiwa, N. and Ruiz, A. and Rauscher, H. and Sirghi, L. and Comoy, E. and Dehen, C. and Challier, L. and Deslys, J. P., 2010, Inactivation of Bacteria and Biomolecules by Low-Pressure Plasma Discharges, Plasma Processes and Polymers 7, 3-4

[6] Stapelmann, K., Fiebrandt, M., Raguse, M., Awakowicz, P., Reitz, G., Moeller, R., 2013, Utilization of low-pressure plasma to inactivate bacterial spores on stainless steel screws, Astrobiology 13(7), 597-606

[7] Roth, S., J. Feichtinger, and C. Hertel, 2010, Characterization of Bacillus subtilis spore inactivation in lowpressure, lowtemperature gas plasma sterilization processes, Journal of Applied Microbiology 108 (2), 521-531

[8] Denis, B., Steves, S., Semmler, E., Bibinov, N., Novak, W., Awakowicz, P., 2012, Plasma sterilization of pharmaceutical products: From basics to production, Plasma Processes and Polymers 9(6), 619-629

[9] Jacobs, P. and Kowatsch, R., 1993, Sterrad Sterilization System: a new technology for instrument sterilization. Endoscopic Surgery and Allied Technologies 1, 57-58

[10] Okpara-Hofmann, J., Knoll, M., Drr, M., Schmitt, B., and Borneff-Lipp, M. (2005) Comparison of low-temperature hydrogen peroxide gas plasma sterilization for endoscopes using various Sterrad models, Journal of Hospital Infection 59, 280-285

[11] Lerouge, S., Wertheimer, M.R., Marchand, R., Tabrizian, M., Yahia, L., 2000, Effect of gas composition on spore mortality and etching during low-pressure plasma sterilization, Journal of Biomedical Materials Research 51, 128-135

[12] Opretzka, J., Benedikt, J., Awakowicz, P., Wunderlich, J., von Keudell, A., 2007, The role of chemical sputtering during plasma sterilization of Bacillus atrophaeus, Journal of Physics D: Applied Physics 40(9), 2826

[13] Rauscher, H., Kylián, O., Benedikt, J., von Keudell, A., Rossi, F., 2010, Elimination of biological contaminations from surfaces by plasma discharges: chemical sputtering, ChemPhysChem, 11(7), 1382-1389

[14] Fumagalli, F., Kylián, O., Amato, L., Hanus, J., Rossi, F., 2012, Low-pressure water vapour plasma treatment of surfaces for biomolecules decontamination, Journal of Physics D: Applied Physics 45, 135203

[15] Hayashi, N., Tsutsui, S., Tomari, T., Guan, W., 2008, Sterilization of Medical Equipment Using Oxygen Radicals Produced by Water Vapor RF Plasma IEEE Transactions on Plasma Science 36, 1302-1303

[16] Raguse, M., Fiebrandt, M., Stapelmann, K., Madela, K., Laue, M., Lackmann, J.-W., Thwaite, J. E., Setlow, P. Awakowicz, P., Moeller, R., 2016, Improvement of biological indicators by using standardized Bacillus subtilis spore monolayers for the evaluation of study of enhanced spore 
decontamination technologies, Applied and Environmental Microbiology 82(7), 2031-2038

[17] Lackmann, J.-W., Fiebrandt, M., Raguse, M., Kartaschew, K., Havenith, M., Bandow, J. E., Moeller, R., Awakowicz, P., Stapelmann, K., 2016, A Combined Low-pressure Hydrogen Peroxide Evaporation plus Hydrogen Plasma Treatment Method for Sterilization - Part 2: An intercomparison study of different biological systems, Plasma Processes and Polymers accepted

[18] Stapelmann, K., Lackmann, J.-W., Buerger, I., Bandow, J. E., Awakowicz, P., 2014, A H 2 very high frequency capacitively coupled plasma inactivates glyceraldehyde 3-phosphate dehydrogenase (GapDH) more efficiently than UV photons and heat combined, Journal of Physics D: Applied Physics 47(8), 085402

[19] Raguse, M., Fiebrandt, M., Denis, B., Stapelmann, K., Eichenberger, P., Driks, A., Eaton, P., Awakowicz, P., Moeller, R., 2016, Understanding of the importance of the spore coat structure and pigmentation in the Bacillus subtilis spore resistance to low-pressure plasma sterilization, Journal of Physics D: Applied Physics, 49, 285401

[20] http://www.goodfellow.com/E/Polystyrene.html

[21] Giancoli, Douglas C. Physik: Lehr-und Ü̈ungsbuch. Pearson Deutschland GmbH, 2010.

[22] Schaeffer, P., Millet, J., Aubert, J. P., 1965, Catabolic repression of bacterial sporulatuion, Proc. Natl. Acad. Sci USA 54, 704-711

[23] Nicholson, W. L., and Setlow, P., 1990, Sporulation, germination and outgrowth, Molecular biological methods for Bacillus edited by Harwood, C.R., and Cutting, S.M., John Wiley and Sons, Sussex, England, pp. 391-450

[24] Halfmann, H., Bibinov, N., Wunderlich, J., Awakowicz, P., 2007, A double inductively coupled plasma for sterilization of medical devices, Journal of Physics D: Applied Physics, 40(14), 4145

[25] Stapelmann, K., Fiebrandt, M., Styrnoll, T., Baldus, S., Bibinov, N., Awakowicz, P., 2015, Implications of electron heating and non-uniformities in a VHF-CCP for sterilizsation of medical instruments, Plasma Sources Science and Technology 24(3), 034014

[26] Spicher, G., Peters, J., Borchers, U., 1996, Bacillus subtilis and Bacillus staerothermophilus as test organisms or bioindicators: the effect of carrier properties on the resistance to steam, Hyg. Med. 3, 190-195

[27] Guizelini, B. P., Vandenberghe, L. P., Sella, S. R., Soccol, C. R., 2012, Study of the influence of sporulation conditions on heat resistance of Geobacillus stearothermophilus used in the development of biological indicators for steam sterilization, Arch Microbiol., 194(12), 991-999

[28] Fritze, D., and Pukall, R., 2001, "Reclassification of bioindicator strains textitBacillus subtilis DSM675 and textitBacillus subtilis DSM2277 as Bacillus atrophaeus", International Journal of Systematic and Evoltionary Microbiology, 51(1), 35-37

[29] Bebby, M.M., and Whitehouse, C., 1965, "A bacterial spre test piece for the control of ethylene oxide sterilization", Journal of Applied Microbiology, 28(3), 349-360

[30] Muranyi, P., Wunderlich, J., Oliver, F., 2010, "Aseptic packaging of food, basic principles and new developments concerning decontamination methods for packaging materials", Innovation in Food Engineering: New Techniques and Products, CRC Press

[31] Esbelin, J., Mallea, S., Ram, J., Arthur, F., Carlin, F., 2013, "Role of pigmentation in protecting Aspergillus niger conidiospores against pulsed light radiation", Photochemistry and Photobiology, 89(3), 758-761

[32] Muranyi, P., Wunderlich, J., Langowski, H.-C., 2010, "Modification of bacterial structures by a lowtemperature gas plasma and influence on packaging material", Journal of Applied Microbiology, 103(5), 1535-1544

[33] Pottage, T., Macken, S., Walker, J. T., Bennett, A. M., 2012, Meticillin-resistant Staphylococcus aureus is more resistant to vaporized hydrogen peroxide than commercial Geobacillus stearothermophilus biological indicators, J Hosp Infect, 80(1), 41-45

[34] Schumb, W. C., Satterfield, C. N., Wentworth, R. L., 1955, Hydrogen peroxide, Reinhold Publishing Corporation, New York

[35] Pruss, K., S. Stirtzel, and U. Kulozik, 2012, "Influence of the surface temperature of packaging Wiley-VCH 
A combined $\mathrm{H}_{2} \mathrm{O}_{2}$ evaporation and $\mathrm{H}_{2}$ plasma process for sterilization - Part 1

specimens on the inactivation of Bacillus spores by means of gaseous H2O2." Journal of Applied Microbiology 112.3, 493-501

\section{Graphical Abstract}

Plasma sterilization is a promising alternative to conventional sterilization procedures. However, the efficiency of plasma sterilization processes is challenged by multilayered stacks of spores as plasma is a surface process. Furthermore, small, complex metal geometries pose a challenge due to shielding characteristics. A combined process of condensed hydrogen peroxide with subsequent hydrogen plasma treatment is introduced to overcome this challenges. The condensation process is investigated and a proof-ofconcept is given by sterilization tests in a process challenge device and in sealed sterile bags. 

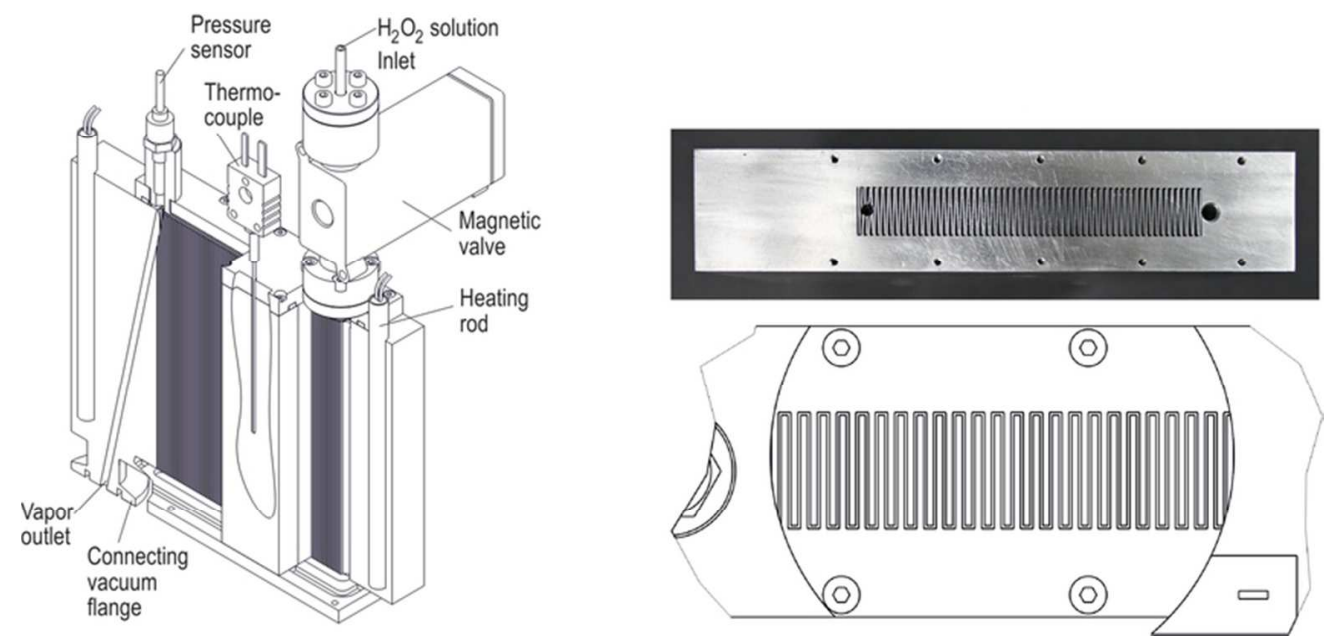

Sketch of the evaporator (left) and the meander-shaped rips of the evaporator (right).

$72 \times 34 \mathrm{~mm}(300 \times 300 \mathrm{DPI})$ 


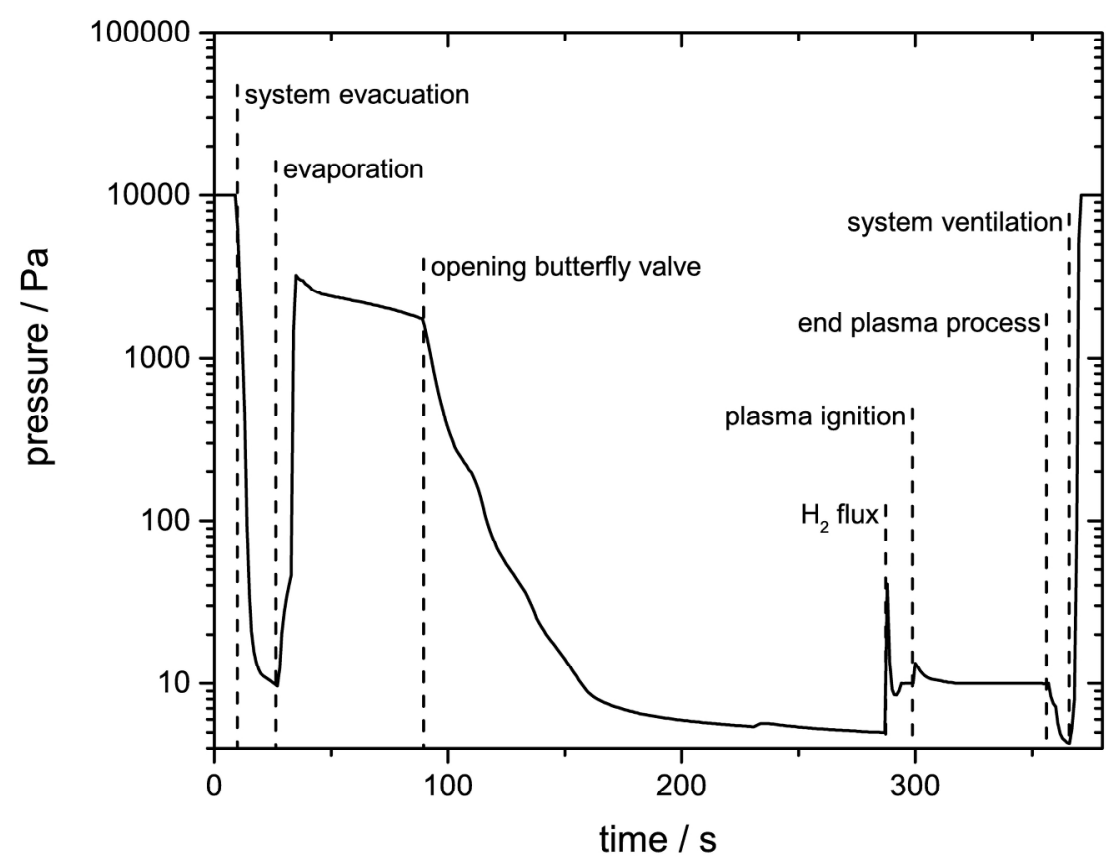

Sequence of the combined process: After system evacuation below $10 \mathrm{~Pa}, 4 \mathrm{ml}$ of $30 \% \mathrm{H}_{2} \mathrm{O}_{2}$ are evaporated at $120^{\circ} \mathrm{C}$. The butterfly valve is closed for $60 \mathrm{~s}$ and opened afterwards. After system evacuation below $5 \mathrm{~Pa}, 20 \mathrm{sccm} \mathrm{H}$ flux is applied at $10 \mathrm{~Pa}$. The plasma is ignited for $60 \mathrm{~s}$ at $400 \mathrm{~W}$. Afterwards, the system is vented again.

$208 \times 159 \mathrm{~mm}(300 \times 300 \mathrm{DPI})$ 


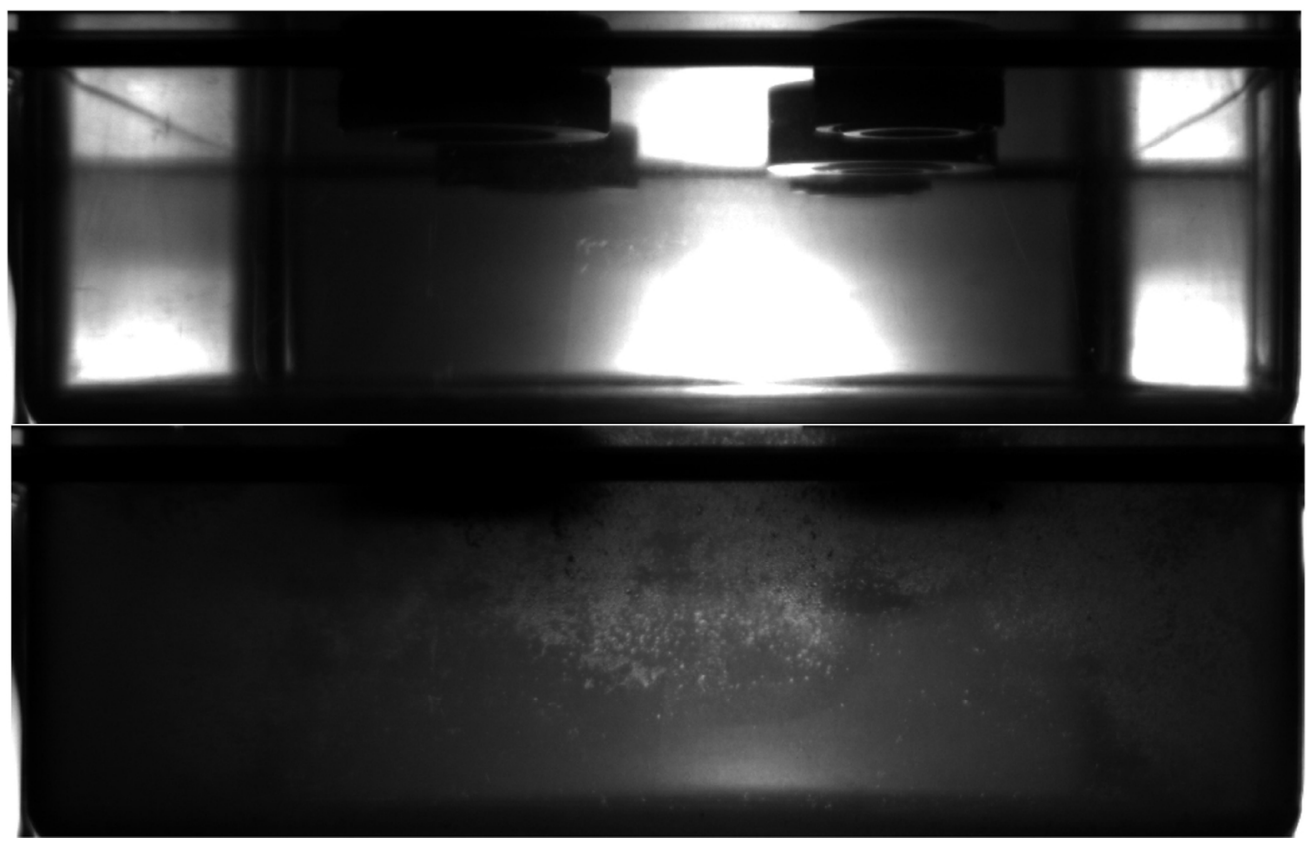

Camera view before (top) and after (bottom) evaporation of $3 \mathrm{ml} 30 \%(\mathrm{w} / \mathrm{w}) \mathrm{H}_{2} \mathrm{O}_{2}$ at $120{ }^{\circ} \mathrm{C}$. In the upper image the different ports to the chamber are visible.

$115 \times 73 \mathrm{~mm}(300 \times 300 \mathrm{DPI})$ 

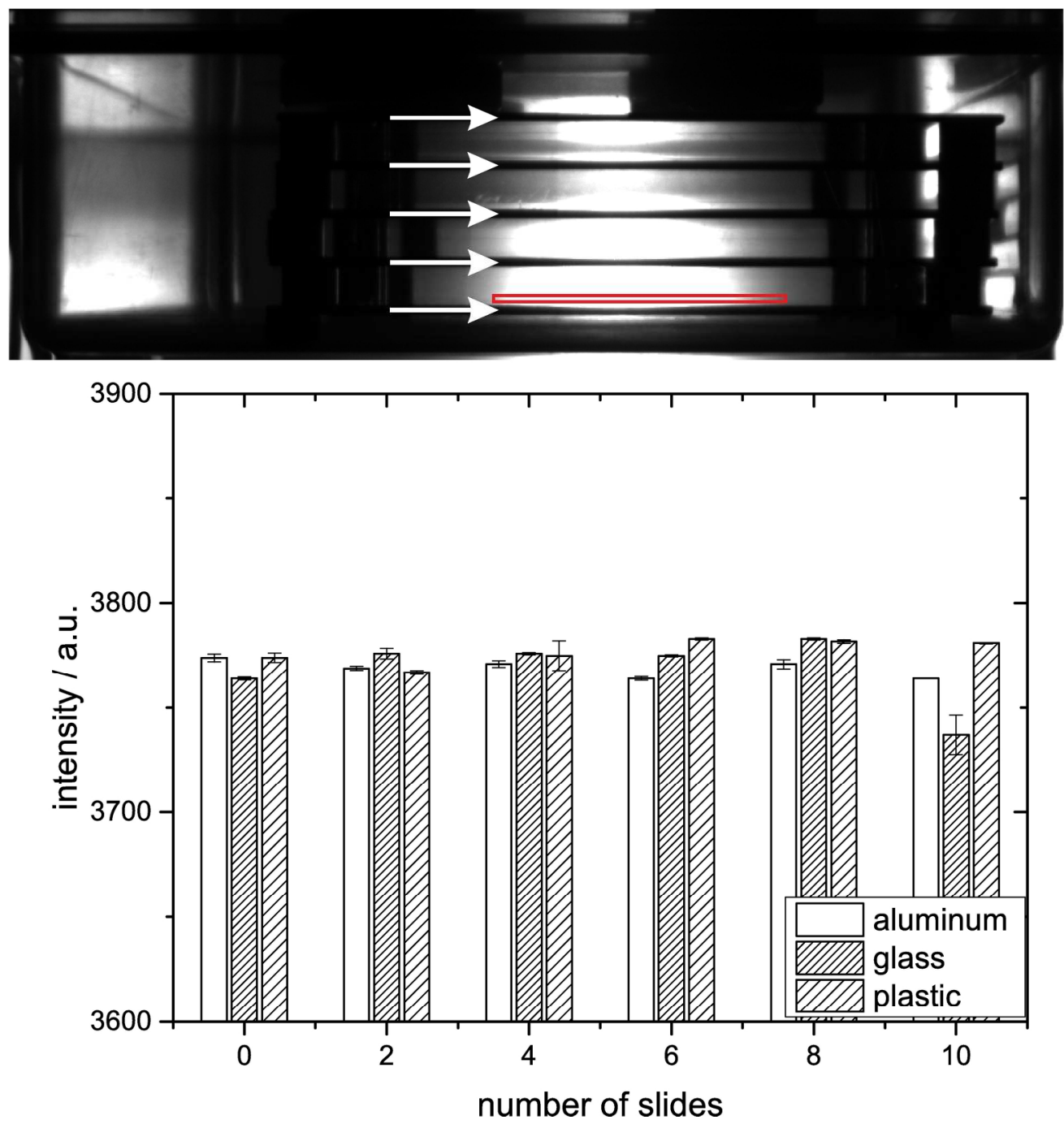

Top: Image of the chamber with 10 slides ( 2 stacks behind each other with 5 slides each). White arrows mark the position of the slides. The red line marks the averaged pixels for measuring the intensity; Bottom: Increasing number of slides does not influence the mean intensity value before evaporation of $\mathrm{H}_{2} \mathrm{O}_{2}$.

$189 \times 198 \mathrm{~mm}(300 \times 300$ DPI $)$ 


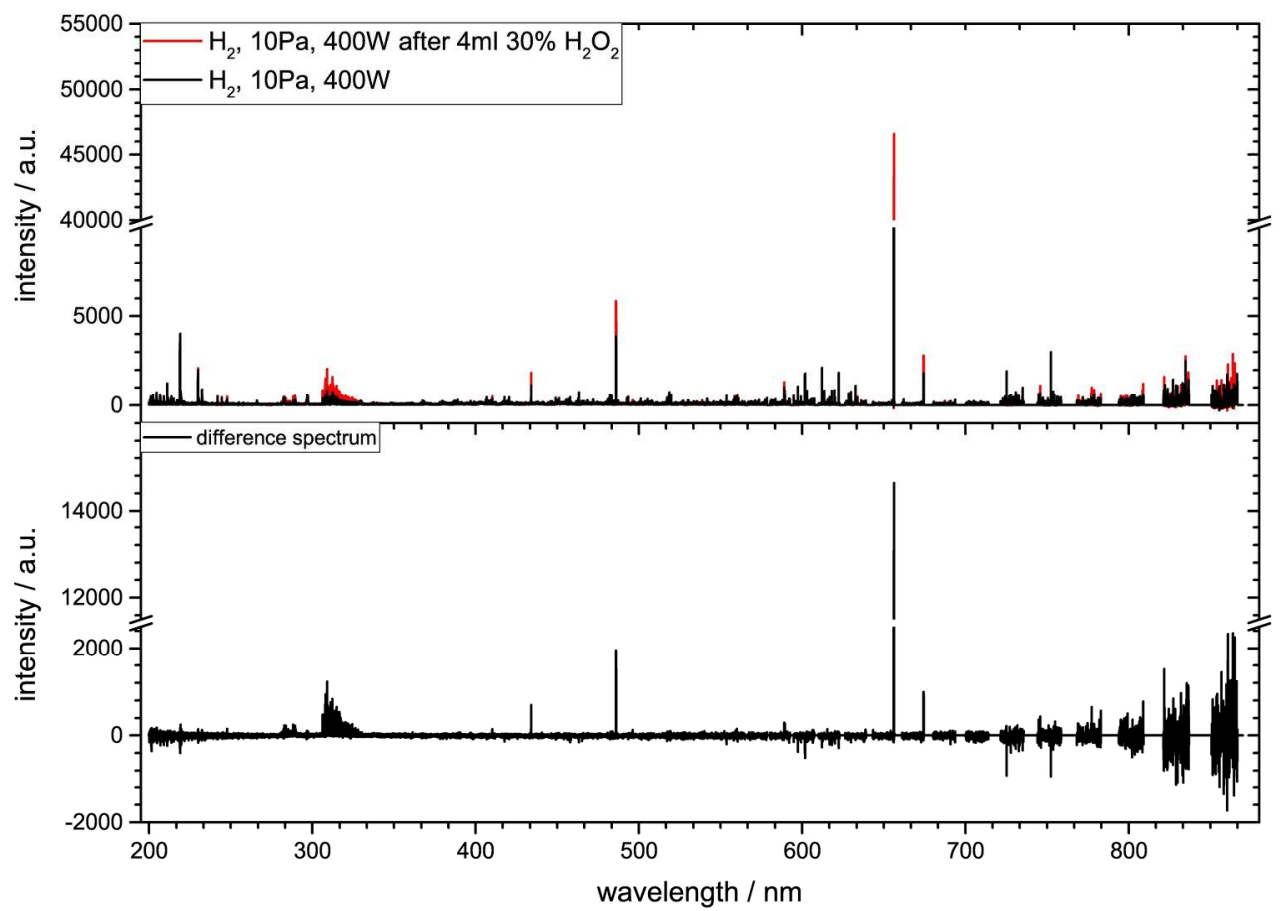

Relative calibrated spectra of the pure plasma process $\left(\mathrm{H}_{2} 10 \mathrm{~Pa}, 400 \mathrm{~W}\right)$ and the combined process (4 ml, $120{ }^{\circ} \mathrm{C}, 30 \% \mathrm{H}_{2} \mathrm{O}_{2}, \mathrm{H}_{2}, 10 \mathrm{~Pa}, 400 \mathrm{~W}$ ) (top) and difference of both spectra (bottom). The difference spectrum shows stronger $\mathrm{OH}$ and Balmer emission after evaporation of $\mathrm{H}_{2} \mathrm{O}_{2}$.

$$
201 \times 141 \mathrm{~mm}(300 \times 300 \text { DPI) }
$$



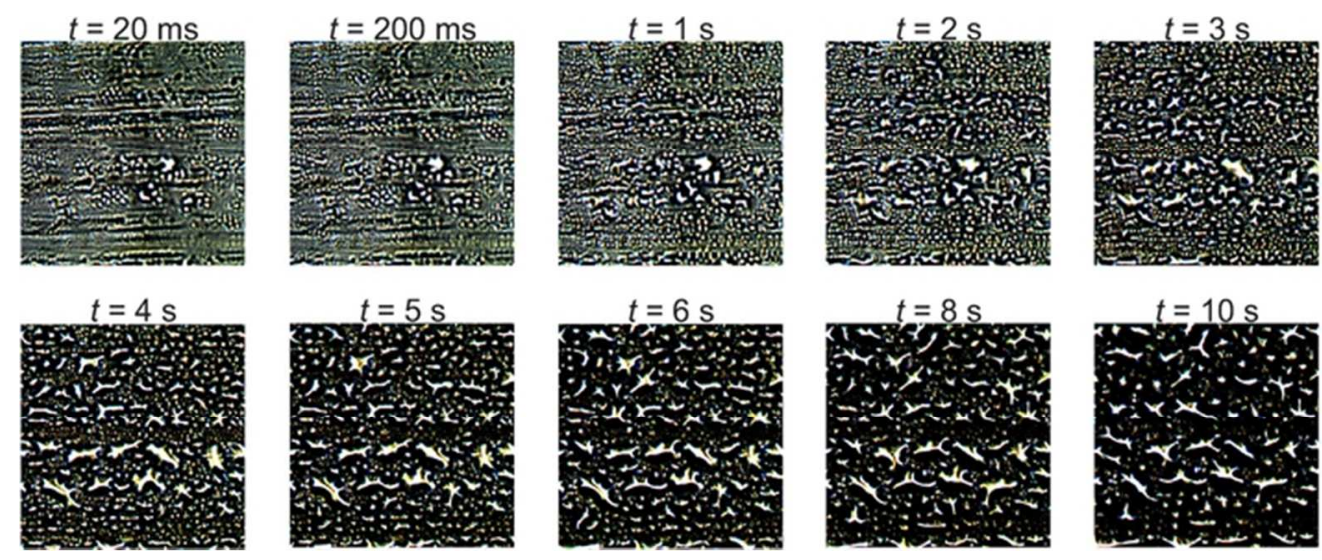

Temporal evolution of droplet size after condensation: Example images of the droplets at different time points after condensation of $4 \mathrm{ml}$ hydrogen peroxide $30 \%$, evaporated at $90^{\circ} \mathrm{C}$, with DSD 4 and $p_{\text {base }}$ $=10 \mathrm{~Pa}$. These pictures were evaluated for different conditions, depicted in figure 7 .

$$
59 \times 24 \mathrm{~mm}(300 \times 300 \text { DPI })
$$



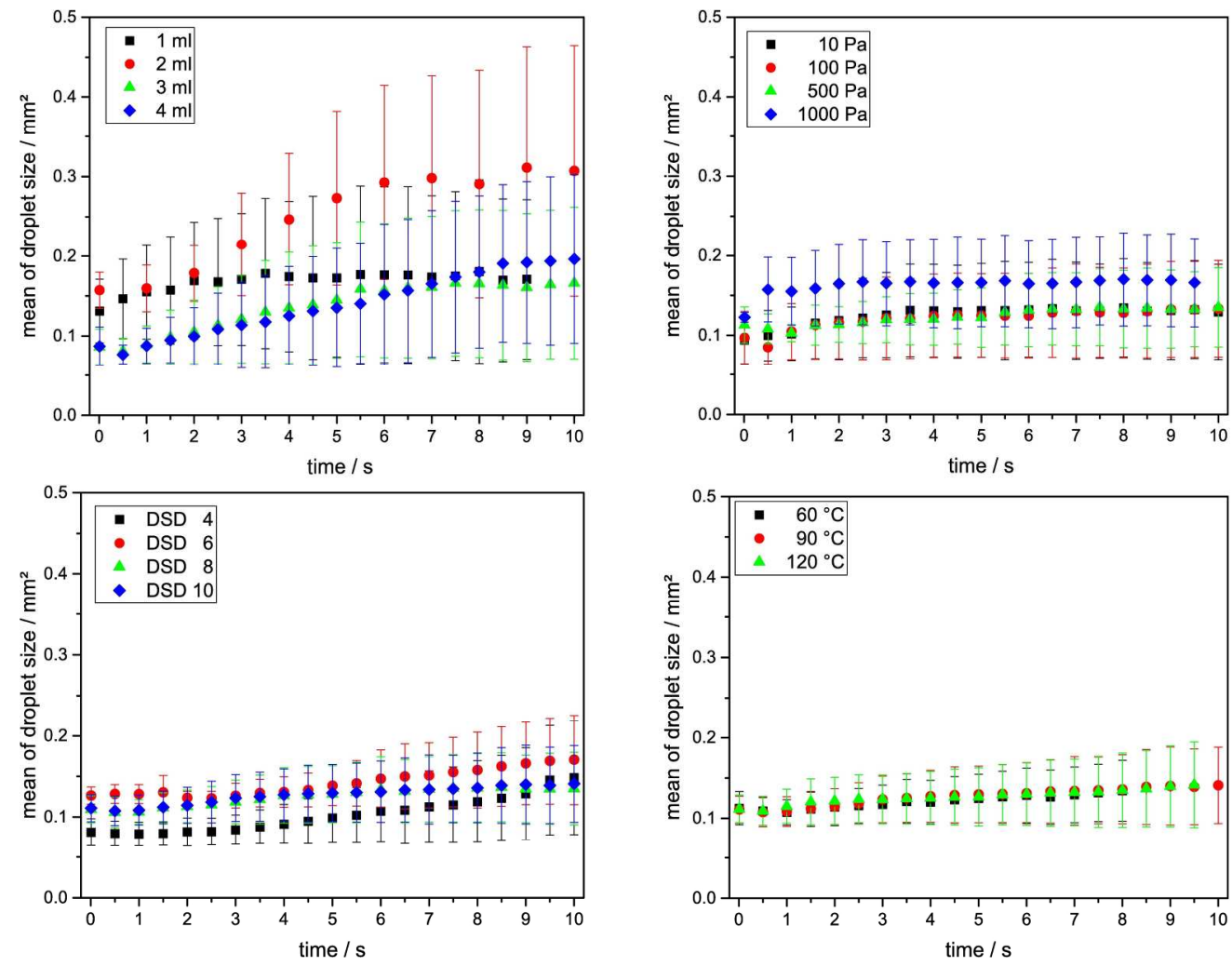

Top Left: Temporal evolution of mean of droplet size depending on the amount of the evaporated liquid. $\mathrm{T}_{\mathrm{V}}$ $=90^{\circ} \mathrm{C}, \mathrm{DSD} 4, \mathrm{p}_{\text {base }}=10 \mathrm{~Pa}$. Top Right: Mean of droplet size for different starting pressures in the process chamber. $\mathrm{T}_{V}=120^{\circ} \mathrm{C}$, DSD 4, $2 \mathrm{ml} \mathrm{H} \mathrm{O}_{2}$. Bottom left: Mean of droplet size for different liquid injection velocities. $\mathrm{T}_{\mathrm{V}}=90^{\circ} \mathrm{C}, \mathrm{p}_{\text {base }}=10 \mathrm{~Pa}, 4 \mathrm{ml} \mathrm{H} \mathrm{H}_{2}$, Bottom right: Mean of droplet size for different evaporator temperatures. $\mathrm{p}_{\text {base }}=10 \mathrm{~Pa}$, DSD $4,4 \mathrm{ml} \mathrm{H} \mathrm{O}_{2}$.

$218 \times 170 \mathrm{~mm}(300 \times 300 \mathrm{DPI})$ 

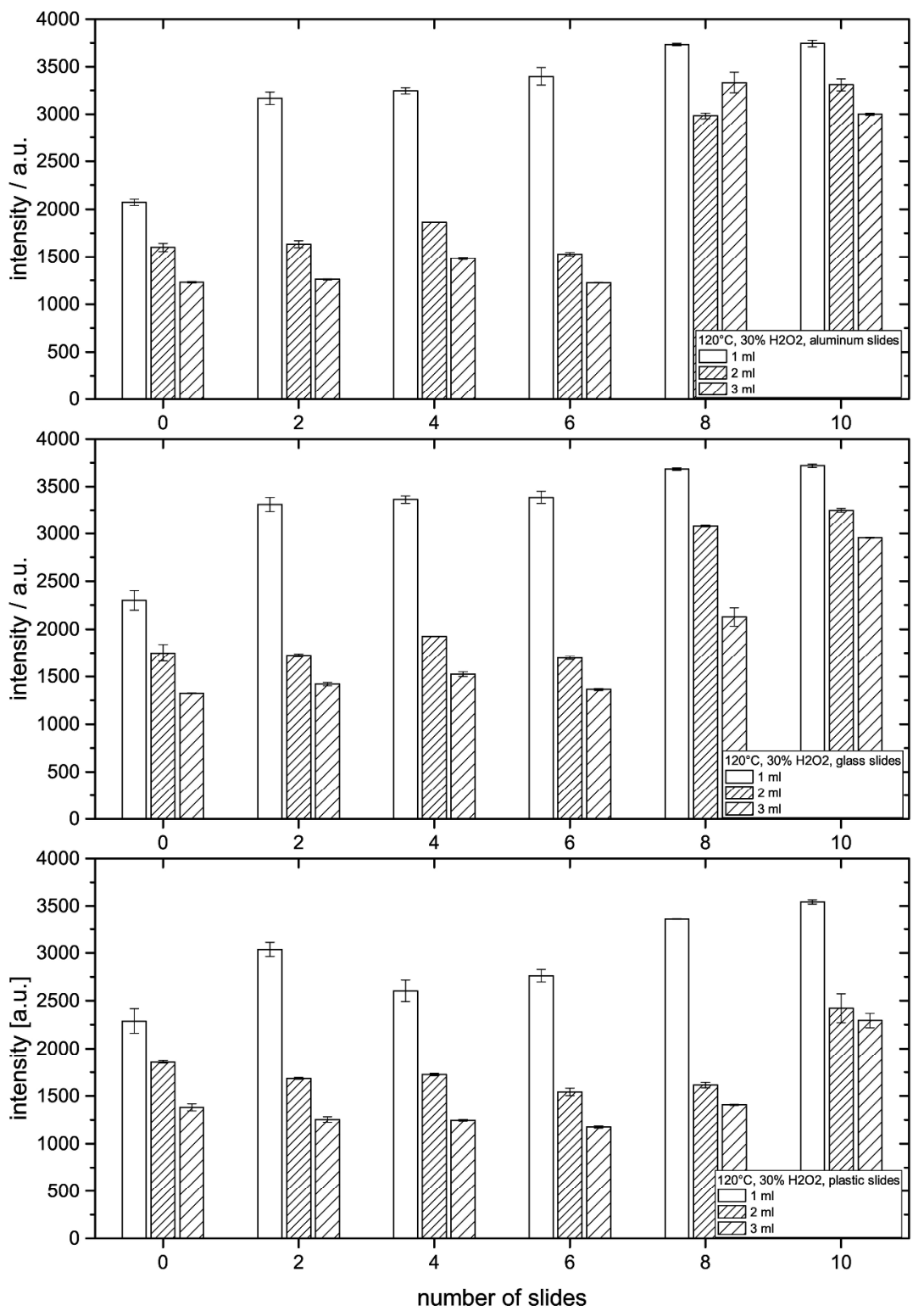

Influence of surface area, surface material and amount of evaporated liquid onto film homogeneity and/or thickness (the lower the intensity, the thicker the liquid film due to absorption and distraction of light): Intensity is depicted for number of slides from 0 to 10 slides of aluminum, glass, and polystyrene as plastic. The amount of hydrogen peroxide $\left(c=30 \%, T_{V}=120{ }^{\circ} \mathrm{C}\right)$ is varied from 1 to $3 \mathrm{ml}$.

$288 \times 412 \mathrm{~mm}(300 \times 300 \mathrm{DPI})$ 


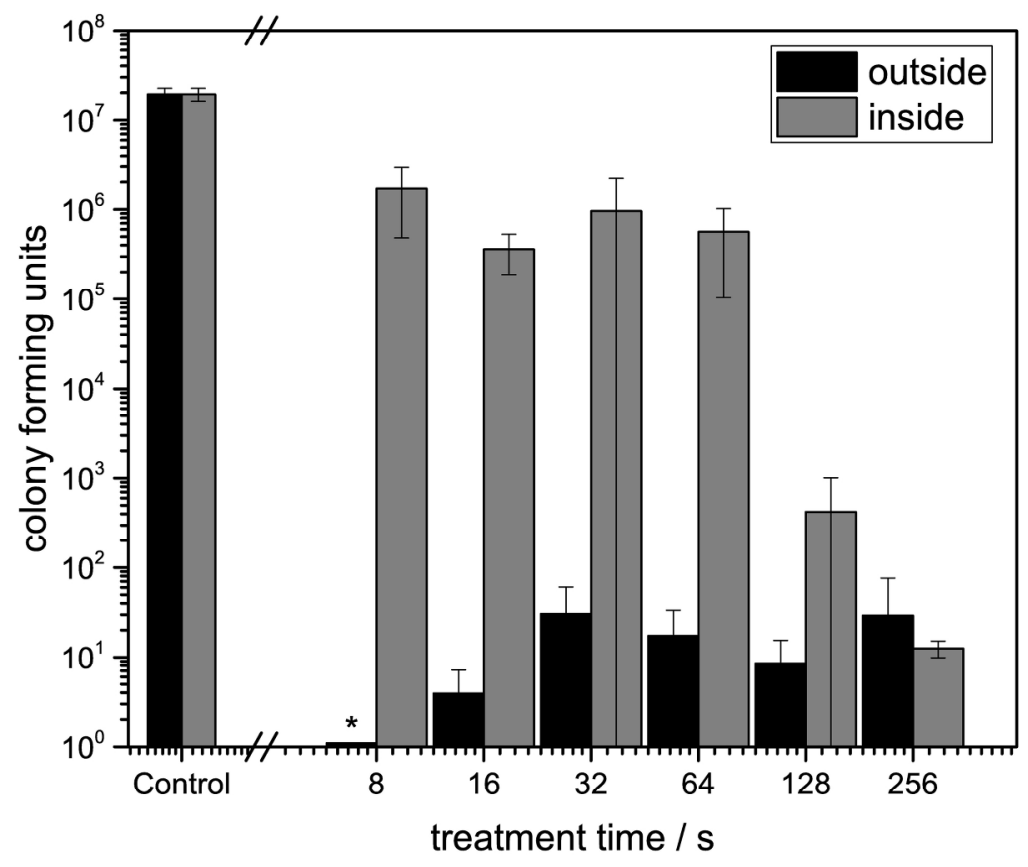

Spore inactivation in a PCD: Colony forming units of Bacillus atrophaeus inside and outside a process challenge device. Experimental conditions were: $4 \mathrm{ml} \mathrm{H}_{2} \mathrm{O}_{2} 30 \%$, DSD4, pase $=10 \mathrm{~Pa}, \mathrm{~T}_{\mathrm{V}}=90^{\circ} \mathrm{C} ; 20 \mathrm{sccm}$ $\mathrm{H}_{2}, \mathrm{P}=400 \mathrm{~W}, \mathrm{p}=10 \mathrm{~Pa}$. The asterisks indicate CFU below detection limit (full spore inactivation).

$208 \times 159 \mathrm{~mm}(300 \times 300$ DPI $)$ 


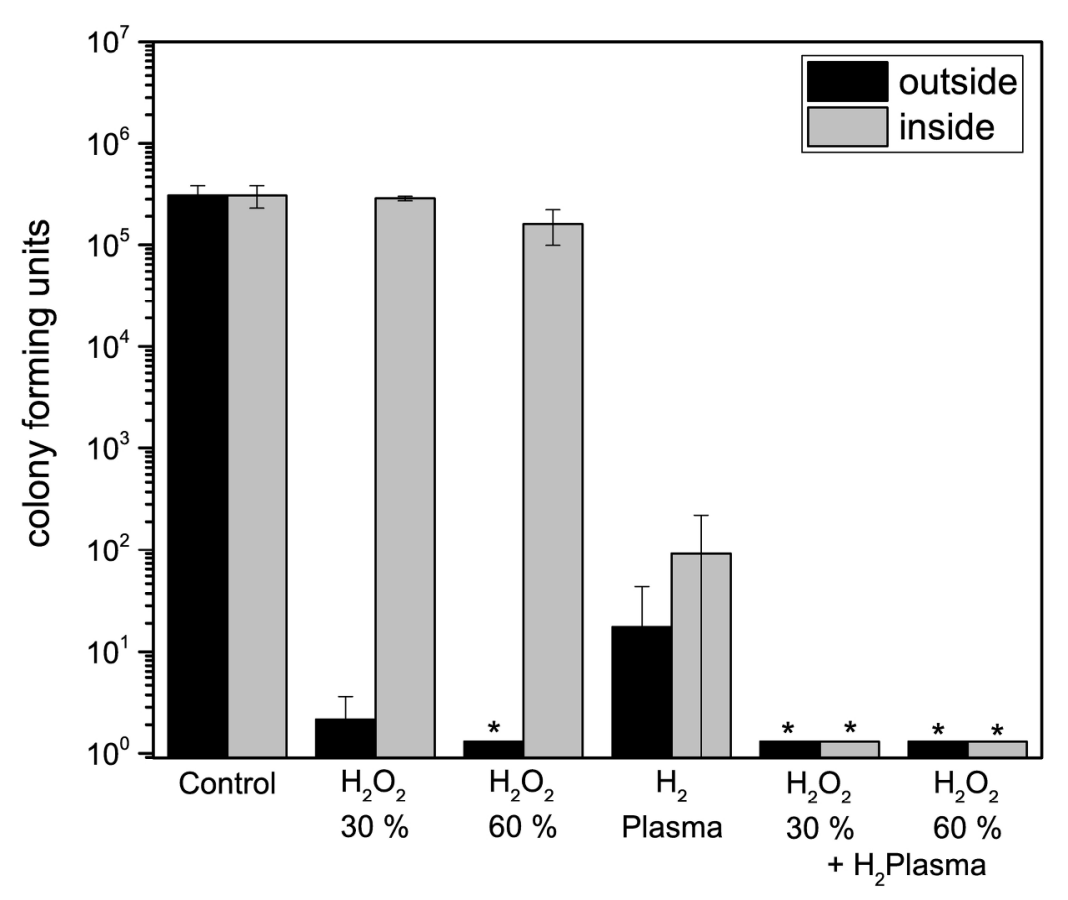

Spore inactivation in sterile bags: Colony forming units of Geobacillus stearothermophilus inside and outside sterile bags after $60 \mathrm{~s}$ treatment time. Experimental conditions were: $4 \mathrm{ml} \mathrm{H}_{2} \mathrm{O}_{2}$, DSD4, $\mathrm{p}_{\text {base }}=10$ $\mathrm{Pa}, \mathrm{T}_{\mathrm{v}}=120^{\circ} \mathrm{C} ; 20 \mathrm{sccm} \mathrm{H}, \mathrm{P}=400 \mathrm{~W}, \mathrm{p}=5 \mathrm{~Pa}$. The asterisks indicate CFU below detection limit (full spore inactivation).

$208 \times 159 \mathrm{~mm}(300 \times 300 \mathrm{DPI})$ 


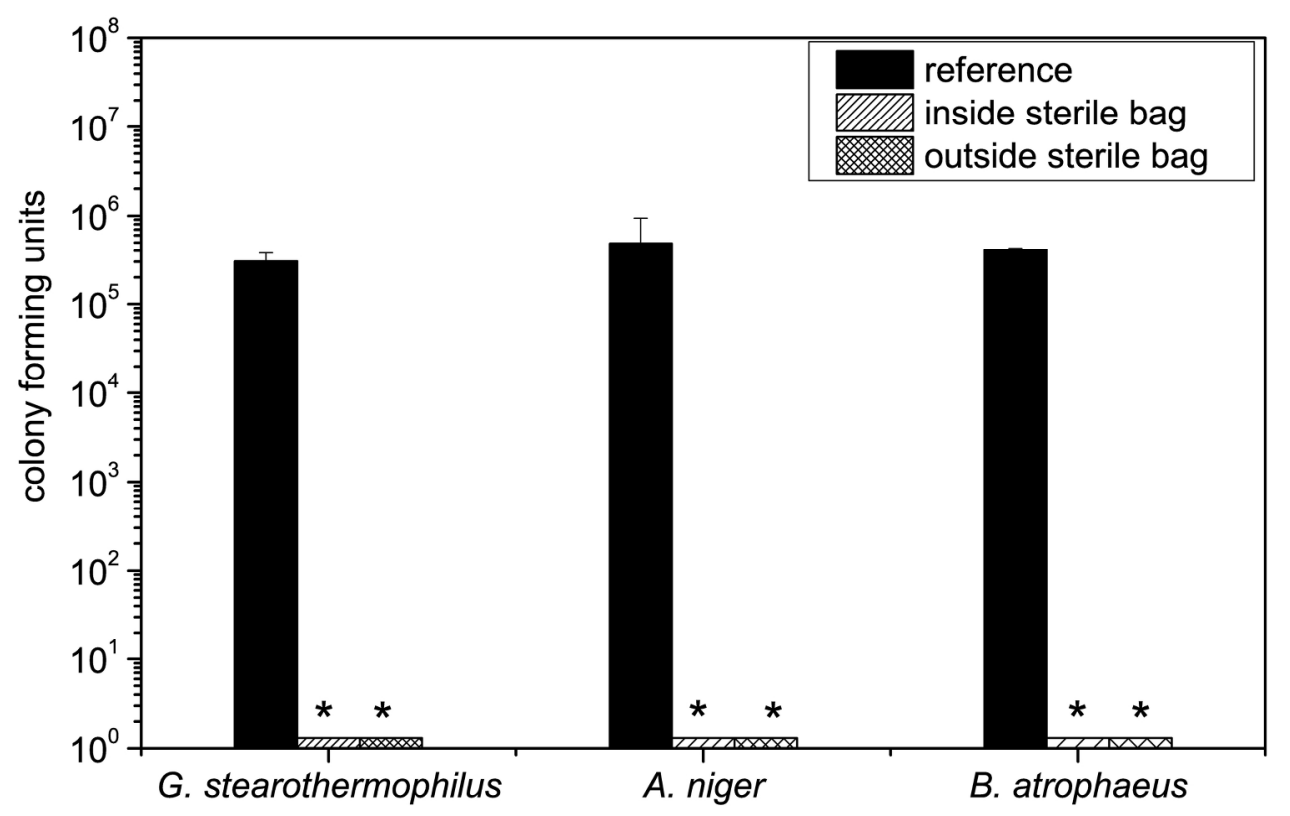

Bacterial and fungal spore inactivation in sterile bags: Colony forming units of Geobacillus stearothermophilus, Aspergillus niger and Bacillus atrophaeus inside and outside sterile bags after $60 \mathrm{~s}$ treatment time. Experimental conditions were: $4 \mathrm{ml} \mathrm{H}_{2} \mathrm{O}_{2} 30 \%$, DSD4, pase $=10 \mathrm{~Pa}, \mathrm{Tv}_{\mathrm{v}}=120^{\circ} \mathrm{C} ; 20 \mathrm{sccm}$ $\mathrm{H}_{2}, \mathrm{P}=400 \mathrm{~W}, \mathrm{p}=5 \mathrm{~Pa}$. The asterisks indicate CFU below detection limit (full spore inactivation).

$201 \times 141 \mathrm{~mm}(300 \times 300$ DPI $)$ 


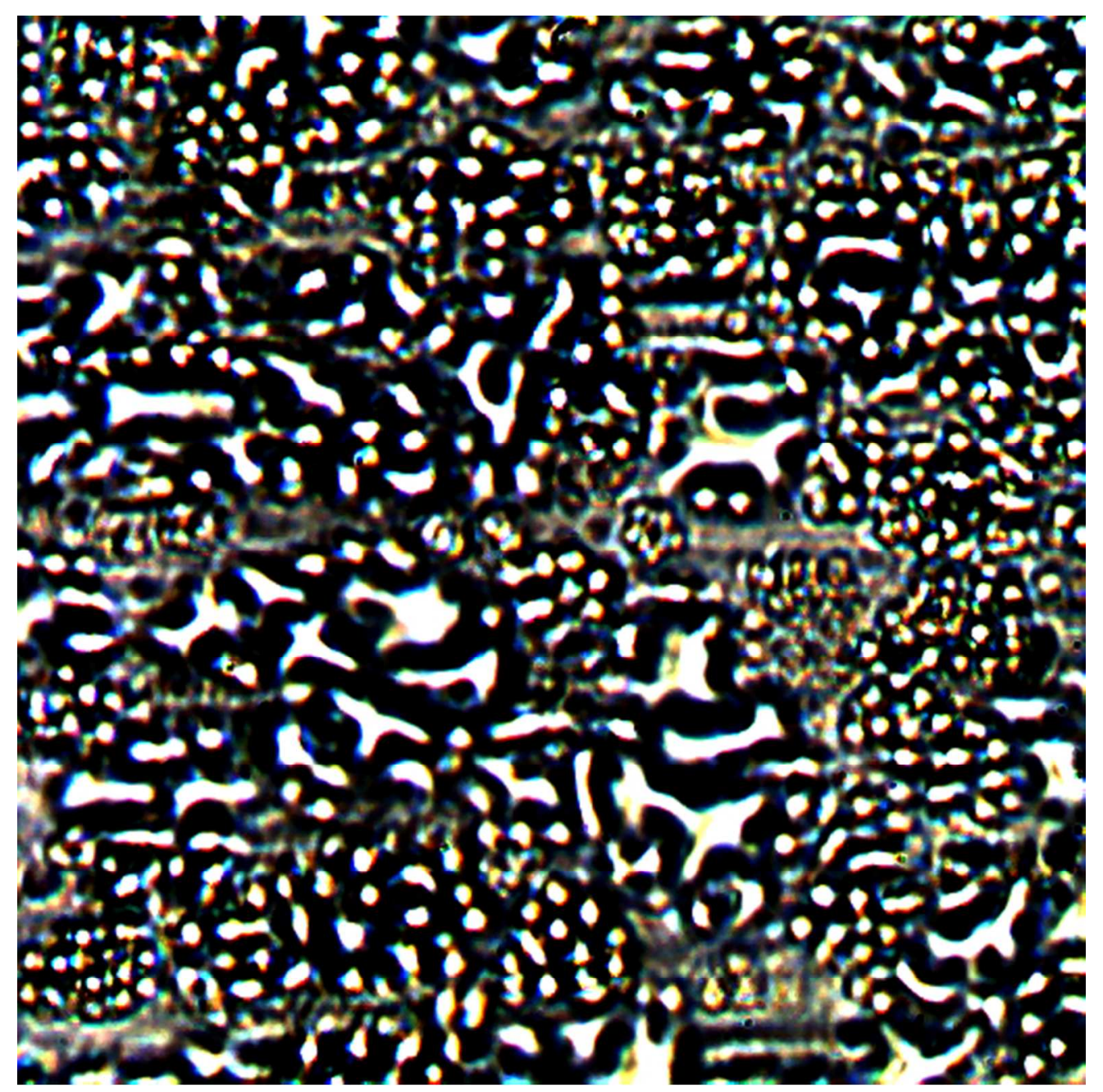

Graphical Abstract: Plasma sterilization is a promising alternative to conventional sterilization procedures. However, the efficiency of plasma sterilization processes is challenged by multilayered stacks of spores as plasma is a surface process. Furthermore, small, complex metal geometries pose a challenge due to shielding characteristics. A combined process of condensed hydrogen peroxide with subsequent hydrogen plasma treatment is introduced to overcome this challenges. The condensation process is investigated and a proof-of-concept is given by sterilization tests in a process challenge device and in sealed sterile bags. 